\title{
Freedom of Movement Restrictions Inhibit the Psychological Integration of Refugees *
}

\author{
Hanno Hilbig ${ }^{\dagger}$ Sascha Riaz ${ }^{\ddagger}$
}

July 25,2022

\begin{abstract}
How do freedom of movement restrictions affect refugee integration? While a growing body of research studies the initial spatial allocation of refugees, there is little causal evidence on subsequent policies that restrict residential mobility. We study a contentious law in Germany, which barred refugees from moving to a location different from the one they were exogenously assigned to. To identify the causal effect of the movement restriction on integration, we utilize a sharp date cutoff that governs whether refugees are affected by the policy. We demonstrate that restricting freedom of movement had pronounced negative effects on refugees' sense of belonging in Germany while increasing identification with their home countries. In addition, the policy decreased engagement in a variety of social activities. Our findings suggest that discriminatory policies send a negative signal about the inclusiveness of the host society and thereby reduce the psychological integration of refugees.
\end{abstract}

\footnotetext{
*We thank Jeremy Bowles, Alisha Holland, Anselm Hager, Macartan Humphreys, Pia Raffler, Alexandra Scacco, Max Schaub, Jonas Wiedner and audiences at WZB Berlin, EuroWEPS, and Harvard for helpful comments.

${ }^{\dagger}$ PhD Candidate, Department of Government, Harvard University hhilbig@g.harvard.edu

$\ddagger$ PhD Candidate, Department of Government, Harvard University riaz@g.harvard.edu
} 


\section{Introduction}

As the number of forcibly displaced people approaches one percent of the world population, the integration of refugees has become a critical public policy challenge. To facilitate integration, governments in destination countries frequently enact restrictive integration policies, ranging from employment bans to limits on religious expression (Abdelgadir and Fouka 2020). The earliest experience of restrictions often comes in the form of initial spatial allocation policies, which have received considerable scholarly attention (see e.g. Bratsberg et al. 2020). Less is known about integration policies that limit residential mobility beyond the initial allocation. However, a large number of countries including Switzerland, the Netherlands, and France either outright prohibit or penalize refugees for leaving their assigned location. Beyond scholarly interest, understanding the impact of such policies has important legal implications. According to a recent ruling by the European Court of Justice, movement restrictions are permissible only if they facilitate the integration of refugees ${ }^{1}$

We study the case of Germany, where a 2016 law forced more than one million refugees to remain at the location they were exogenously assigned to upon arrival in the country (Deutscher Bundestag 2016). While intended to facilitate integration, the effect of such restrictions on residential mobility is unclear. Proponents of the restriction argue that permitting refugees to freely choose their place of residence results in the formation of urban ethnic enclaves, reducing incentives to assimilate (see Cutler, Glaeser and Vigdor 2008). On the other hand, the policy makes it harder for refugees to find jobs through local ethnic networks and may hence slow down their integration into the German labor market (see also Damm 2014). Finally, movement restrictions may lead refugees to view the host society as discriminatory, inhibiting their willingness to integrate (Adida, Laitin and Valfort 2014).

To estimate the causal effect of the movement restriction, we leverage a sharp date cutoff that governs the application of the policy. The policy bans refugees whose asylum applications were approved after January 1, 2016 from relocating. We exploit this discontinuity and compare otherwise similar refugees within a small bandwidth around this treatment assignment cutoff. Drawing on a

\footnotetext{
${ }^{1}$ Court of Justice of the European Union (CJEU) cases C443/14 and C444/14.
} 
panel survey of about 5,000 refugees, we estimate the causal effect of movement restrictions on indicators for contact, feelings of belonging, social engagement, and economic integration, measured in 2017 and 2018.

We first document that restricted refugees were not significantly more likely to relocate than those who are not restricted. We then demonstrate that movement restrictions made refugees markedly more pessimistic about their employment prospects in Germany. Turning to measures of identity and belonging, we find pronounced negative effects. Affected refugees felt less welcome in Germany, identified more strongly with their home countries, and participated less in social activities. Notably, the effects on belonging persist for two years, while the effect on social engagement is only observed in 2017 but not 2018. However, we do not find that restrictions affected the frequency of contact with natives, co-ethnics, or other immigrants. Finally, we do not observe negative effects on labor market integration, as employment is higher among restricted refugees in the second wave of the survey we use. However, we emphasize that this effect may stem from the fact that employment exempts refugees from the movement ban, and therefore incentivizes them to seek employment.

Taken together, our results suggest that restricting residential mobility negatively affects refugees' social engagement and feelings of belonging. In the absence of effects on relocation decisions, we argue that movement restrictions hinder the psychological integration of refugees because such discriminatory policies send a negative signal about the inclusiveness of the host society. Strikingly, a policy that was designed to prevent ethnic segregation and the entrenchment of separate communities resulted in stronger identification with refugees' country of origin.

Our results contribute to a growing literature on restrictive or exclusionary policies that affect minority populations, such as restrictions on religious expression (Abdelgadir and Fouka 2020), citizenship (Avitabile, Clots-Figueras and Masella 2013) or language education (Fouka 2019). Related prior work has either employed cross-national survey data to examine country-level policies that affect immigrants in destination countries, (see e.g. Fleischmann and Dronkers 2010), or has leveraged within-country variation to analyze policies that restrict immigrant entry (see e.g. CobbClark 2003). Building on this research, our work is among the first to examine domestic movement 
restrictions within a destination country, using a causal research design that complements crossnational research by mitigating potential confounding that arises when comparing policies across countries. Our study also adds to the literature on how initial contextual conditions after arrival shape integration. While prior work on initial allocation policies has focused on the role of local economic and social conditions, we demonstrate how the legal environment of the host country can have a crucial impact on integration trajectories ${ }^{2}$

\section{Background}

Spatial dispersion policies are typically enacted to prevent the formation of ethnic enclaves. Such policies rest on the assumption that, when allowed to move freely, refugees would sort into residential areas with a high concentration of refugees or other immigrants. This derives from the general concept of social homophily - a preference for being around others who are similar to themselves, allowing for easier communication and cooperation (Cutler, Glaeser and Vigdor 2008). Prior research has yielded mixed results on the effects of ethnic segregation. On the one hand, as ethnic enclaves provide immigrants access to social networks and economic opportunities, they might reduce incentives to assimilate (see e.g. Lazear 1999). At the same time, ethnic networks can facilitate labor market integration of refugees by disseminating job information and improving the job-worker match quality (Damm 2014, Martén, Hainmueller and Hangartner 2019, see also section A.2 for additional references and more discussion on the potential effects of the policy)

Discriminatory policies can inhibit refugee integration even without directly affecting relocation decisions. Movement restrictions are an intrusion into a fundamental liberty - the right to freely choose one's place of residence. As movement restrictions generally only apply to refugees, they send a strong negative signal about the inclusiveness of the host society. Discriminatory policies may entrench group identities, rendering assimilation and psychological integration more costly. Prior research has shown that institutionalized discrimination has negative effects on immigrant integration. Adida, Laitin and Valfort (2014) provide evidence that Muslims in France are reluctant to assimilate, in part because they perceive French institutions as systematically discriminatory. This aligns with recent research by Abdelgadir and Fouka (2020), who find that a

\footnotetext{
${ }^{2}$ We elaborate more on our contribution in sections A.5 and A.6 in the Supporting Information (SI).
} 
national headscarf ban in France reduced the educational attainment of Muslim girls and lowered their sense of belonging in French society. Restrictive policies can aggravate the already precarious state of subjective well-being and mental health of many refugees after fleeing from war and persecution (Fazel, Wheeler and Danesh 2005). One contribution of our study is therefore to go beyond the observation that limiting mobility may affect immigrants through locational characteristics. Rather, one of our goals is to ascertain whether the policy itself is perceived as exclusionary, and could therefore hamper psychological integration.

\section{Movement restrictions in Germany}

Beginning in 2015, Germany experienced an unprecedented inflow of refugees. Today, refugees constitute more than two percent of the country's population. To facilitate the integration of refugees into German society, the government passed the wide-ranging Integrationsgesetz ('integration law') in August 2016. The law introduced mandatory movement restrictions for refugees in Germany, motivated by (i) the desire to prevent enclave formation and (ii) calls to equally distribute the costs of integrating refugees across the country. We provide additional information on the implementation of the policy in section A.1. on its relevance in section A.2 and on the media coverage and public discourse in section A.3.

After arriving in Germany, refugees are exogenously allocated to one of the 16 federal states through a computer algorithm. The total number of refugees a state receives is proportional to its population size and tax revenue. Within each state, refugees are then allocated to counties. With few exceptions, the number of refugees a county receives is proportional to its population size. The allocation of refugees to counties is independent of the individual characteristics of the refugees. Therefore, we would not expect that certain types of refugees are more likely to be placed in, for example, urban areas. The August 2016 movement restriction policy requires approved refugees to reside in the state that they were initially assigned to for a period of three years. Seven large states, accounting for $73 \%$ of Germany's population, further require that refugees must live in the specific county that they were assigned to (see also section A.14.3 for additional details). The policy prevents refugees from freely choosing their place of residence but does not prohibit them from traveling within the country. 


\section{Data and empirical strategy}

Our main data source is the IAB-BAMF-SOEP Survey of Refugees in Germany (SOEP), a panel of about 5,000 refugees surveyed in 2016, 2017, and 2018.3 In addition to demographics, asylum status, and labor market indicators, the survey contains several items on refugee integration. We focus on outcome variables measuring social contact, participation in social activities, feelings of belonging, and labor market integration. Most of our outcomes are measured twice after the policy was enacted, in 2017 and 2018. We provide summary statistics on all variables in tables A.1 and A.2. In table A.3, we list the survey questions corresponding to the outcomes used in our main analysis. For data protection reasons, we do not have information on the county or city where refugees reside. We provide additional details on the SOEP survey in section A.4 in the supporting information (SI).

Refugees are only subject to the movement restriction policy if their asylum application was approved after January 1, 2016. To estimate the causal effect of movement restrictions on integration, we compare refugees who are similar with respect to background characteristics, arrived in Germany at the same time, but whose asylum applications were approved right before or after the treatment assignment cutoff. Importantly, we do not estimate the effect of relocating on integration, but rather the effect of being subject to the movement restriction.

We use a matching design to implement our identification strategy. We first subset our sample to applications approved between November 2015 and February 2016, resulting in a two-month bandwidth around the assignment cutoff. We then match each treated unit to all control units with exactly the same covariate values. Our covariates are age (discretized), origin country, gender, education, and the quarter-year of arrival in Germany. We form blocks of treated and control units around the treatment assignment cutoff, such that within each block, all units (treatment and control) have the same covariate values. By design, covariate balance is perfect within blocks. Across blocks, the treated and control group are balanced on all relevant covariates (see figure

\footnotetext{
${ }^{3}$ The effective sample size depends on the bandwidth, outcome, and survey year. In our preferred specification, it ranges between 194 and 242 for most outcomes (see table A.5 in the SI).
} 
A.1). After matching, we estimate OLS models with block fixed effects of the following form:

$$
y_{i, j}=\alpha+\tau D_{i}+\sum_{j=2}^{M} \beta_{j} B_{i, j}+\epsilon_{i}
$$

Here, $y_{i, j}$ is the outcome variable observed for individual $i$ nested in covariate-block $j . D_{i}$ is a binary indicator for the treatment assignment and equals one if a refugee's asylum application was approved after January 1, 2016. We thus code refugee's treatment status following the legal provisions of the Integrationsgesetz. We estimate a total of $M=47$ (2017) or $M=45$ (2018) block fixed effects $\beta_{j}$ in the case of a two-month bandwidth, where $B_{i, j}=1$ if individual $i$ is a member of covariate-block $j$. The key parameter of interest is $\tau$, the effect of the movement restrictions. We use heteroskedasticity-robust standard errors for all of our analyses. Exemptions from the policy can be granted if refugees take up employment, vocational training, or distant tertiary education (see section A.1 for more details). We do not match on these variables to avoid post-treatment bias. As compliance with the policy is likely not perfect, we are estimating the intent-to-treat effect of the movement restriction policy.

Our identification strategy requires that the timing of approval decisions around the January 1 cutoff is uncorrelated with unobserved individual or institutional characteristics. In section A.13, we provide evidence in support of this identification assumption. Among other things, we document that treated and untreated refugees are statistically indistinguishable in terms of premigration characteristics and outcomes measured prior to the enactment of the policy. Finally, we emphasize that sorting around the treatment assignment cutoff is not a concern. All asylum decisions in our matched sample were made between November 2015 and February 2016, several months before the integration law was passed in August 2016. To our knowledge, the possibility of a sharp date cutoff was first discussed in May 2016 (see also section A.1 in the SI). Refugees and local bureaucrats were unaware of the sharp date cutoff when asylum decisions were made.

\section{Results}

First, we show that restrictions had little effect on refugee movement. In figures A.6 and A.7 in the SI, we however demonstrate that unrestricted refugees are not significantly more likely to 
move between two survey waves than those refugees whose movement is restricted. We discuss potential reasons for this finding in section A.11 in the SI.

Figure 1: Effect of movement restrictions on integration

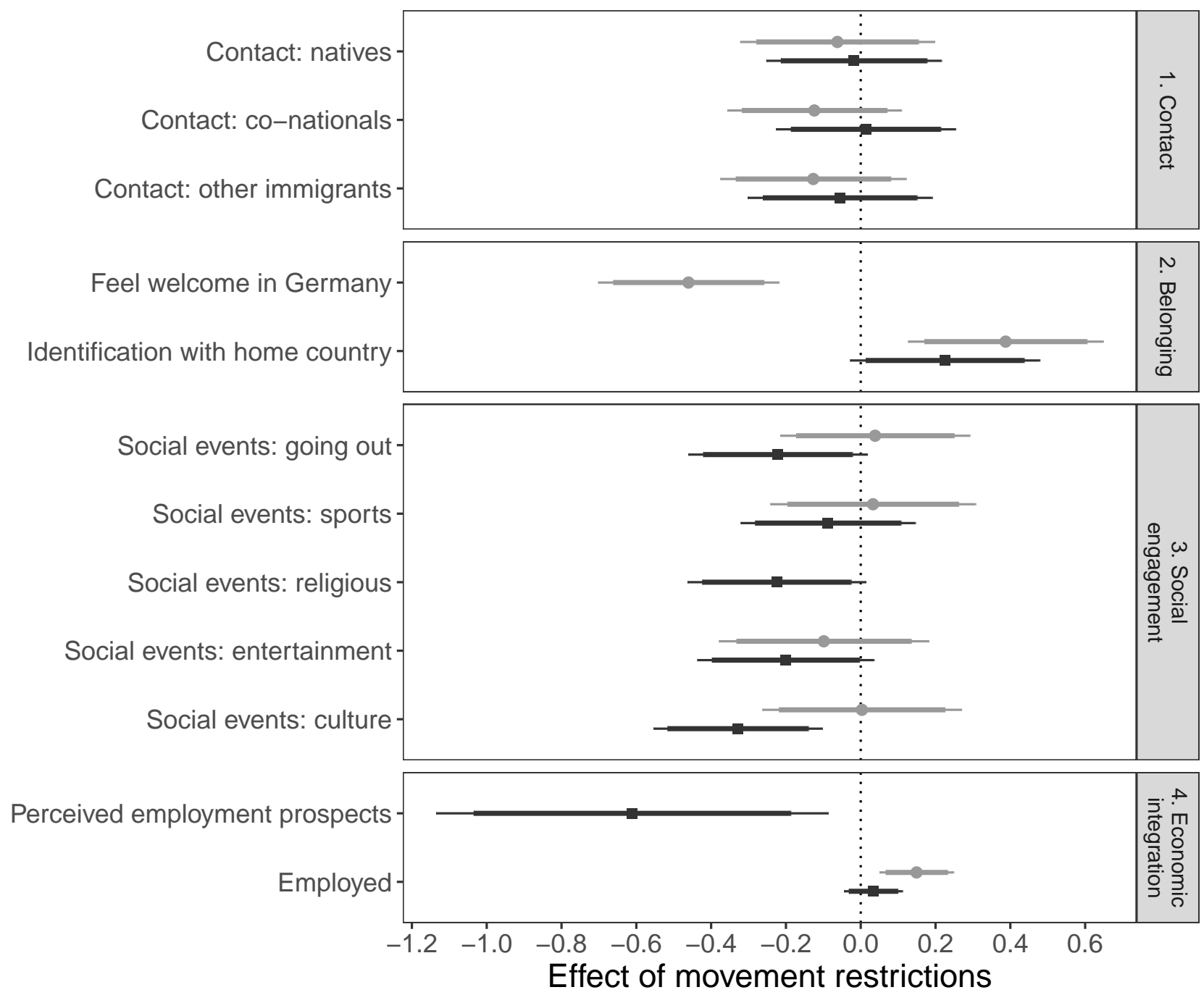

$\rightarrow$ Surveyed in $2017 \multimap$ Surveyed in 2018

Note: The figure shows estimated effects movement restrictions on the outcomes listed on the left-hand side. The horizontal bars represent 90\% (thick lines) / 95\% (thin lines) confidence intervals. All variables are standardized except employment status, which is binary. The sample is based on a two-month bandwidth around the Jan 1, 2016 cutoff. The sample size is between 194 and 242 for all outcomes except perceived employment prospects, where it is 67 . More details are given in table A.5 in the SI.

In figure 1, we present the main effects of the relocation ban, separately for the 2017 and 2018 survey waves 4 Our first set of outcomes considers contact with natives, co-nationals, and other immigrants. We observe point estimates close to zero for all outcomes, suggesting that movement

\footnotetext{
${ }^{4}$ Not all survey items were asked in both years. We present pooled results in figure A.16
} 
restrictions had little effect on contact. Moving to the two items that measure belonging in Germany, we find that the policy led to a 0.5 standard deviation decrease in the degree to which refugees feel welcome in Germany. Conversely, the strength of identification with their respective home countries increased substantially. These effects are already present in 2017 but persist into the year 2018, two years after the policy was enacted. Regarding social engagement, we observe negative effect estimates of similar magnitude across all five social engagement items in 2017. These effects are not observed in 2018.

The negative effects we observe for social engagement may at first seem inconsistent with our results on contact, where we find no detectable differences between restricted and unrestricted refugees. However, it is important to note that about two thirds of the refugees are married and hence likely attend social events with their families. For this large subgroup, the decreased frequency of attending social events does not automatically translate into decreased contact with natives or other refugees. Given the small bandwidth around the date cutoff we consider in our analysis, we therefore cannot rule out effects on contact for the subgroup of unmarried refugees.

Regarding labor market integration, we first show that restricted refugees were initially much more pessimistic about their labor market prospects. However, we find no difference in employment in 2017, while employment among restricted refugees is higher in 2018 than among unrestricted refugees. The employment result should be considered in light of (i) the incentives created by the movement restrictions and (ii) the fact that additional employment is often in low-wage occupations. Refugees were incentivized to find employment, as this exempts them from the movement restriction (see section A.1).$^{5}$ Second, most employed refugees end up in jobs that pay relatively low wages. At 1,500 euros per month, the median net household income of employed refugees in our sample falls just below the national poverty line. Yet, the employment effects contrast the negative effect on belonging and therefore suggest that the effects of the policy should not be viewed as uniformly positive or negative.

What explains the negative effect of the movement restriction on feelings of belonging and

\footnotetext{
${ }^{5}$ We note that the qualitative evidence we present in section A.16 suggests that refugees indeed sought for employment in order to gain an exemption from the policy.
} 
social engagement? We provide two pieces of evidence that the movement restriction sent a negative signal about the inclusiveness of German society. First, we draw on qualitative interviews with affected refugees to illustrate how the policy was perceived as discriminatory, led to social withdrawal, and reduced refugees' sense of belonging in Germany (see section A.16). In section A.15.2 in the appendix, we provide additional evidence that the movement restriction reduced life satisfaction among affected refugees, which is consistent with the primary mechanism we propose. Finally, we note that this mechanism likely does not operate primarily through reduced employment prospects. While we find that the policy induced skepticism about employment in 2017, we observe either null or positive effects on employment. As a result, we argue that the downstream employment consequences of the policy matter less than the fact that the policy signals that the government is willing to afford refugees fewer rights than natives.

In addition to the main results, section A.13 in the SI contains a series of robustness checks. Among other things, we provide evidence that faster asylum decisions do generally not correlate with individual integration outcomes, and that our results are robust across different model specifications and bandwidths. Finally, we test for effect heterogeneity along four dimensions: i) urbanity (figure A.23), ii) city-states (figure A.24), iii) within-state movement restrictions (figure A.25), and iv) refugee education prior to arrival (figure A.26). We find evidence that the negative effects of the policy on social engagement are stronger for highly educated refugees. Moreover, we also observe that ethnic networks may alleviate some of the effects of the policy, as refugees in city-states do not experience effects on identification with their home countries.

\section{Conclusion}

Does restricting residential mobility benefit or hinder refugee integration? In this paper, we provide causal estimates of the effect of domestic movement restrictions after the 2015 refugee influx in Germany. We show that movement restrictions negatively affect integration, especially with respect to social engagement and belonging. We argue that the observed effect likely stems from the negative signal discriminatory policies send about the inclusiveness of the host society. In section A.16 in the SI, we provide additional qualitative evidence towards this point. We document that restricted refugees express feelings of alienation and withdrawal in response to the inability 
to change their place of residence. However, we find a positive effect on employment, which is generally considered one of the most important integration outcomes.

While we can only speculate about the long-term consequences of the movement restriction policy, prior research has demonstrated that ethnic discrimination can have important long-term consequences (Wallace, Nazroo and Bécares 2016). This suggests that the negative effects of the policy might persist, at least in the medium term. Finally, we emphasize that we estimate the impact of movement restriction for the subset of refugees in the vicinity of the assignment cutoff. We therefore caution against over-generalizing our results to movement restrictions that apply to different populations or in other contexts. Finally, we acknowledge that qualitative interviews only allow us to touch the surface of the individual-level mechanisms driving our results. More research is needed on how individual refugees perceive discriminatory policies, and how this affects different stages of the integration process.

\section{References}

Abdelgadir, A. and V. Fouka. 2020. "Political Secularism and Muslim Integration in the West: Assessing the Effects of the French Headscarf Ban." American Political Science Review pp. 1-17. Adida, C. L., D. D. Laitin and M. Valfort. 2014. "Muslims in France: Identifying a Discriminatory Equilibrium." Journal of Population Economics 27(4):1039-1086.

Avitabile, C., I. Clots-Figueras and P. Masella. 2013. "The Effect of Birthright Citizenship on Parental Integration Outcomes." The Journal of Law and Economics 56(3):777-810.

Bratsberg, B., J. Ferwerda, H. Finseraas and A. Kotsadam. 2020. "How Settlement Locations and Local Networks Influence Immigrant Political Integration." American Journal of Political Science pp. 1-15.

Cobb-Clark, D. A. 2003. "Public Policy and the Labor Market Adjustment of New Immigrants to Australia." Journal of Population Economics 16(4):655-681.

Cutler, D. M., E. L. Glaeser and J. L. Vigdor. 2008. "When Are Ghettos Bad? Lessons from Immigrant Segregation in the United States." Journal of Urban Economics 63(3):759-774.

Damm, A. P. 2014. "Neighborhood Quality and Labor Market Outcomes: Evidence from Quasi- 
Random Neighborhood Assignment of Immigrants." Journal of Urban Economics 79:139-166. Deutscher Bundestag. 2016. "Gesetzentwurf Der Fraktionen Der CDU/CSU Und SPD: Entwurf Eines Integrationsgesetzes." https://dserver.bundestag.de/btd/18/086/1808615.pdf.

Fazel, M., J. Wheeler and J. Danesh. 2005. "Prevalence of Serious Mental Disorder in 7000 Refugees Resettled in Western Countries: A Systematic Review." Lancet 365:1309-1314.

Fleischmann, F. and J. Dronkers. 2010. "Unemployment among Immigrants in European Labour Markets." Work, Employment and Society 24(2):337-354.

Fouka, V. 2019. "Backlash: The Unintended Effects of Language Prohibition in US Schools after World War I." The Review of Economic Studies .

Lazear, E. P. 1999. "Culture and Language." Journal of Political Economy 107(6):95-126.

Martén, L., J. Hainmueller and D. Hangartner. 2019. "Ethnic Networks Can Foster the Economic Integration of Refugees." Proceedings of the National Academy of Sciences 116(33):16280-16285. Wallace, S., J. Nazroo and L. Bécares. 2016. "Cumulative Effect of Racial Discrimination on the Mental Health of Ethnic Minorities in the United Kingdom." American Journal of Public Health 106(7):1294-1300. 


\section{A Supporting Information (Online Only)}

\section{Contents}

A.1 Details on the movement restriction policy . . . . . . . . . . . . . . . . . . . 3

A.2 Rationales for studying movement restrictions . . . . . . . . . . . . . . . . . . . . 4

A.2.1 Details on the relationship between movement restrictions and enclave formation, economic outcomes, and integration . . . . . . . . . . . . . 5

A.3 Media coverage of the movement restrictions . . . . . . . . . . . . . . . . . . . . . 9

A.4 Additional information on SOEP survey data . . . . . . . . . . . . . . . . . . . . 11

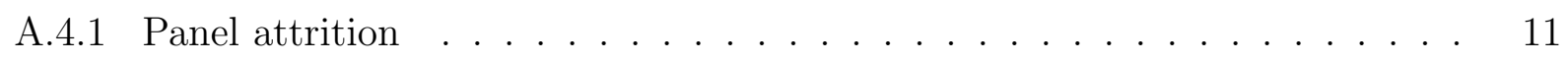

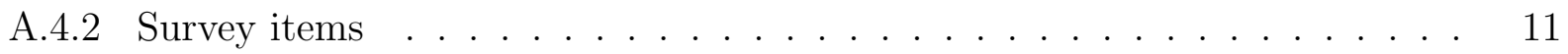

A.4.3 Information on the asylum decision date . . . . . . . . . . . . . . 11

A.5 Details on the contribution of the paper . . . . . . . . . . . . . . . . . . 12

A.6 Initial allocation policies and movement restrictions . . . . . . . . . . . . . . . . . 14

A.7 $\quad$ Summary statistics and details on survey outcomes . . . . . . . . . . . . . . . . . 16

A.8 Pre-treatment covariate balance . . . . . . . . . . . . . . . . . . . . . . . . 19

A.9 Average responses by distance to January 2016 cutoff . . . . . . . . . . . . . . . . 20

A.10 Movement within Germany conditional on asylum approval date . . . . . . . . . . 24

A.11 Effect on relocations within Germany . . . . . . . . . . . . . . . . . . . . . . . . 25

A.12 Detailed main results . . . . . . . . . . . . . . . . . . . . . . 27

A.13 Robustness . . . . . . . . . . . . . . . . . . . . . 28

A.13.1 Omitting block FEs . . . . . . . . . . . . . . . . . . 32

A.13.2 Controlling for covariates instead of block FEs . . . . . . . . . . . . . . . 33

A.13.3 Omitting selected covariates . . . . . . . . . . . . . . . . . 34

A.13.4 Results based on one-to-one matching . . . . . . . . . . . . . . . . . . 35 
A.13.5 Bandwidth sensitivity . . . . . . . . . . . . . 36

A.13.6 Randomization inference . . . . . . . . . . . . . . . . . . . . . . 38

A.13.7 Pooling 2017 and 2018 survey waves . . . . . . . . . . . . . . . . . . 40

A.13.8 Regression discontinuity estimates . . . . . . . . . . . . . . . . . . . . 41

A.13.9 Effect on outcomes measured prior to treatment (placebo) . . . . . . . . . 43

A.13.10 Omitting non-Syrians . . . . . . . . . . . . . . . . . 44

A.13.11 Balance on pre-migration characteristics . . . . . . . . . . . . . . 45

A.13.12 Effect of application decision speed on outcomes . . . . . . . . . . . . . . 47

A.13.13 Effect of pre-migration covariates on application decision speed . . . . . . 48

A.14 Heterogeneity . . . . . . . . . . . . . . . . . . . . . . . 49

A.14.1 Differential effects in urban and rural areas . . . . . . . . . . . . . . . . . 49

A.14.2 Differential effects in city states . . . . . . . . . . . . . . . . 50

A.14.3 Differential effects in states with and without county movement restrictions 51

A.14.4 Differential effects conditional on education . . . . . . . . . . . . . . . 53

A.15 Additional outcomes . . . . . . . . . . . . . . . . . . . . . 56

A.15.1 Effect on German language acquisition, integration course participation and interest in contact with Germans . . . . . . . . . . . . . . . . . . . 56

A.15.2 Effects on life satisfaction . . . . . . . . . . . . . . . . . . 58

A.16 Qualitative evidence for the mechanism . . . . . . . . . . . . . . . . 60 


\section{A.1 Details on the movement restriction policy}

The movement restriction does not apply to refugees who are in employment, work for at least 15 hours per week, and earn at least 710 euros per month. The movement restriction also does not apply to refugees who are in vocational training or are enrolled at a university. Additional exemptions can be granted for short-term job training programs. Exemptions are granted at the family level, i.e. if one family member satisfies at least one condition for an exemption, all family members are exempted from the movement restriction policy. Exemptions are generally granted when the asylum decision is announced.

To the best of our knowledge, the first draft of the policy was released on May 31st, 2016 (Deutscher Bundestag 2016). This may have induced some refugees who closely follow German news to relocate in anticipation of the impending ban. This would pose a problem if there were differential behavioral responses to the policy announcement around the approval date cutoff.

Importantly, both refugees and local bureaucrats were unaware of the assignment cutoff prior to June 2016. Even after June 2016, the date cutoff was only mentioned in drafts of legal documents published by German ministries, exclusively in German language. It is however possible that a small minority of refugees might have been aware of the date cutoff prior to August 2016 and swiftly moved within a few weeks to avoid the restriction.

While important, we do not believe that this mechanism should introduce systematic bias into our results. We also note that as of June 2016, it was unclear whether the policy would be applied retroactively (i.e. whether refugees who moved between January and August 2016 would have to return to their initial location).

Because we only observe refugees once per year in the SOEP panel, we cannot empirically disentangle the exemptions from the policy from its possible effects. For example, it is possible that a refugee was not affected by the policy because he or she was in full-time employment. However, it is also possible that the policy itself affected the likelihood of finding employment.

Conditioning on employment in such a setting can induce post-treatment bias. Therefore, we do not include variables related to exemptions in our matching procedure. For our analysis, this 
implies that we are estimating the intent-to-treat effect of the movement restriction, as compliance with the policy is likely not perfect.

We note that natives generally do not know the treatment status of refugees, unless refugees disclose this information. We therefore view it as unlikely that differential behavior by natives is the main mechanism driving our results.

We also note that regulations that govern location decisions while asylum applications are processed differ from the movement restriction that we discuss.

\section{A.2 Rationales for studying movement restrictions}

In addition to the discussion in the main body of the paper, we now discussed the stakes of the policy, as well as the potential effects on immigration outcomes in more detail.

Stakes of the policy: We emphasize that the movement restriction policy was (and continues to be) hotly debated, both in the public sphere and among politicians. In addition, the policy constitutes a significant intrusion into individual liberties for a large number of refugees. As such, it affects a vulnerable population, with a large share of refugees undertaking a dangerous journey to escape war.

A large number of refugees received an asylum decision that resulted in them being affected by the movement restriction between January 2016 and June 2021 (Bundeszentrale für politische Bildung 2021). As laid out in the introduction of the paper, the policy remains controversial. This is reflected in a report by the Committee on Civil Liberties, Justice and Home Affairs of

the German Parliament (Hausding 2019). In a discussion on whether the policy should be continued, representatives of the German cities, towns, and counties strongly supported an indefinite extension of the movement restrictions. The representatives argued that the policy prevents the formation of ethnic enclaves - abandoning the policy would reduce integration and lead to an unequal distribution of the costs of integrating refugees. In contrast, representatives of several civil society organizations (such as the Paritätischer Gesamtverband or the Deutscher Caritasverband) criticized the policy. In their view, the legality of the policy is dependent on positive effects on refugee integration, which, in their view, have not materialized. What is more, the actors from 
civil society have raised negative consequences of the policy. In regions where housing demand outstrips supply, restricted refugees have to remain in communal accommodations for longer amounts of time, as they cannot seek private accommodations in other locations.

\section{A.2.1 Details on the relationship between movement restrictions and enclave for- mation, economic outcomes, and integration}

In the introduction of the paper, we posit that there are reasons to believe that movement restrictions may affect the formation of ethnic enclaves, economic outcomes, and refugee integration. We now provide an additional discussion of the relationship between these outcomes and movement restrictions.

Ethnic enclaves: As we document in section A.3, the possibility of enclave formation was frequently mentioned as one reason to limit refugee movement. In particular, politicians were worried that integration would not succeed in areas where there is a high concentration of refugees. Prior evidence from other contexts suggests that the expectation that refugees would cluster in certain locations was warranted. Damm (2014) shows that refugees in Denmark sorted into neighborhoods after the initial, quasi-random assignment to municipalities (see also Damm (2009) for a discussion on the characteristics of refugees that relocate to ethnic enclaves).

We note that our paper does not include a direct test of the effect of movement restrictions on enclave formation. This is due to the fact that we cannot precisely observe where refugees live or move to. However, we argue that the discussion of the enclave implications of the policy is nevertheless relevant for our study. The reasons for this are as follows: First, the prevention of enclave formation was one of the major reasons to enact the policy in the first place (see the discussion in sections 3 and A.3. Therefore, we believe that an analysis of the policy benefits from a discussion of the enclave implications. Second, while we do not include a direct test of whether movement restrictions limit enclave formation, we do present results on whether the policy did indeed affect refugee relocation decisions. In section A.11, we demonstrate that the policy did not have significant effects on movement decisions. This implies that the policy may have smaller effects on enclave formation than suggested by some of the proponents of restricting 
refugee movement. Third, we conduct a number of analyses that relate to contextual moderators of the effects of the policy. While these analyses do not directly address the question of whether movement restrictions prevent enclave formation, some of these analyses do relate to the question of whether contexts where the share of co-ethnics or other immigrants is higher moderate the effects of the policy. In figure A.24, we present suggestive evidence that the effects on identification with refugees' home countries in 2018 are more pronounced in non-city states compared to city-states (Stadtstaaten). Possibly, this can be explained by the fact that the negative psychological effect of the policy is alleviated when refugees are surrounded by others that are like them. This is consistent with the discussion of qualitative evidence in section A.16, where we document that refugees perceive the policy in a negative manner when they are placed in communities with few co-ethnics or other immigrants.

Economic outcomes: The rationale for why movement restrictions might affect economic outcomes is most directly connected to regional variation in ethnic networks and the availability of employment. As Damm (2014) and Martén, Hainmueller and Hangartner (2019) demonstrate, ethnic networks can serve to transmit information about employment opportunities, and may therefore result in higher employment among refugees. Movement restrictions prevent some refugees from accessing these networks if they are assigned to a location where there are few other refugees, co-ethnics, or other immigrants. Therefore, movement restrictions may limit economic opportunities if refugees cannot access what (Martén, Hainmueller and Hangartner 2019) terms "ethnic social networks". As a result, refugees affected by the restrictive policy may experience adverse economic outcomes because they cannot move to a location with more favorable contextual characteristics.

In addition to the more general expectation that movement restrictions hinder labor market integration because they limit access to ethnic networks, the specific nature of the German movement restriction policy gives rise to another possible effect on employment. As we discuss in section 4, refugees can be exempted from the movement restrictions if they take up employment in a location that they would ordinarily not be permitted to move to. Consequently, movement restrictions may actually result in a greater likelihood of employment among those who are af- 
fected, as refugees may seek to circumvent movement restrictions by taking up employment. This mechanism is supported by a report by Barth (2019) (see also section A.16), who conducts qualitative interviews with refugees and documents how frustrations with the movement restrictions induce some refugees to seek employment.

Refugee integration: Movement restrictions may affect refugee integration through (i) the fact the policy signals discrimination to affected refugees, (ii) the fact that inability to relocate may lead to differential contextual effects on integration. First, a possible effect of movement restrictions is that refugees receive a signal about the inclusiveness of the host society (see also the discussion in section 2). Regardless of the consequences for location decisions, local context or employment, the fact that some refugees are denied the basic right of free movement may lower their willingness to integrate into the host society. This has been document by prior work such as Adida, Laitin and Valfort (2014), Abdelgadir and Fouka (2020). As Abdelgadir and Fouka (2020) discuss, discrimination can negatively affect psychological well-being. Relatedly, Oskooii (2016) remarks that being subject to perceived mistreatment can result in feelings of inferiority, insecurity, powerlessness, and depression among minority populations. In turn, may be less willing to integrate into the host society, as measured by feelings of belonging, contact, social engagement, or labor market outcomes. In addition, experiences of discrimination may lead refugees to identify more strongly with their own ethnic group or home country - a phenomenon that Rumbaut (2008) terms "reactive ethnicity". If refugees feel more connected to their own ethnic or national identity, they may be less willing to adjust to German society.

In addition to a psychological mechanism, the relationship between movement restrictions and local contexts may affect integration outcomes. This mechanism most directly relates to the political discussion around the movement restrictions. As discussed in section A.3, politicians that supported the policy were concerned that "integration cannot succeed" (BILD 2016c) in areas with high concentrations of refugees. Similar arguments have been proposed in the literature on ethnic segregation - immigrant or refugee populations that cluster in specific locations may exhibit lower levels of language proficiency or contact of natives Cutler and Glaeser 1997; Edin, Fredriksson and Aslund 2003). This can occur when when refugees reside in locations where they can access 
basic needs, economic opportunities or social networks that are provided by co-ethnics or other immigrants. When exposed to people like themselves, refugees may retain their own characteristics for a longer amount of time (Cutler, Glaeser and Vigdor 2008), and may have reduced incentives to learn the language of the host society or integrate into native social networks. The effect of movement restrictions on contact with natives, social engagement and feelings of belonging to the host society may therefore be positive if the restrictive policy does indeed prevent the formation of heavily segregated areas where refugees experience reduced exposure to natives. Crucially, potential effect of movement restrictions on integration that rest on changes in locational context require that the restrictions do actually induce changes in movement when comparing affected and unaffected refugees (see also section A.11 for a discussion on how the policy affected the propensity to relocate). 


\section{A.3 Media coverage of the movement restrictions}

The introduction of the movement restriction was extensively discussed in the German media. Politicians from all major parties and representatives from various societal groups and associations expressed their views on the policy. The discourse revolved around three key topics: 1) preventing the formation of spatial clusters with a high concentration of immigrants ('ghettos'), 2) that refugees are a 'burden' to hosting communities that should be evenly distributed across the country, and 3) competition for social services between refugees and natives. We illustrate this discourse using original articles from the Bild Zeitung, which is by far the largest daily newspaper in Germany.6 The media coverage of the policy was similar in other outlets such as Die Welt.

First, media coverage of the movement restriction emphasized the possibility that the refugee influx of 2015/16 might lead to the formation of ethnic enclaves. The pejorative term 'ghetto' was frequently used in this context. The Minister of the Interior in the state of Baden-Württemberg, Thomas Strobl, justified the policy on the grounds that "there will be no refugee ghettos in BadenWürttemberg, in which integration cannot succeed" (BILD 2016c). The CDU faction in the state parliament of Lower Saxony likewise expressed fears that the refugee influx would lead to the 'formation of ghettos' in large cities (WELT 2017).

The policy was also framed as an instrument to manage competition for social services and public goods between refugees and natives. Most frequently, competition for affordable housing in big cities was cited as a justification for the restrictive policy. The Minister of Integration (Integrationsminister) of North Rhine-Westphalia justified the introduction of the restrictive policy as follows: "cities, given their linguistic and cultural diversity are attractive for refugees. However, we cannot ignore the fact that we are creating large inequalities North Rhine-Westphalia if we do not intervene with policy instruments. Some cities are overburdened with the integration of refugees, others do have spare resources" (Wir in NRW - Das Landesportal 2016). The Association of Towns and Municipalities (Städte und Gemeindebund), a special interest organization for German municipalities, called for the implementation of the movement restriction to reconcile

\footnotetext{
${ }^{6}$ In 2016, the Bild reached about $15 \%$ of German adults. The Welt, SZ, and FAZ each only reach about 1-2\% of the German adult population (Marktforschung Axel Springer SE 2021 ).
} 
the shortage of affordable housing in large cities with vacant housing in rural areas (BILD 2017). The implication was that not all inhabitants of Germany ought to compete equally for affordable housing in large cities; rather, the association implicitly called for the prioritization of German citizens over refugees. The association also labeled the integration of refugees a 'herculean task' (BILD 2016a). In an interview with the Stuttgarter Nachrichten, the mayor of Stuttgart expressed a similar sentiment: "Stuttgart does not have enough housing space for all recognized refugees that would like to live in Stuttgart. Therefore, I think it is reasonable to restrict residential mobility, which is also in the interest of refugees" (BILD 2016d). Mayors from other cities echoed this view (BILD 2016b). Apart from housing, the policy was also framed in terms of competition between refugees and natives for other social services. The mayor of Magdeburg for instance, a medium-sized city in East Germany, suggested that a movement restriction was necessary to manage the surge in demand for child daycare due to the refugee influx. 


\section{A.4 Additional information on SOEP survey data}

\section{A.4.1 Panel attrition}

We observe $60 \%$ of the respondents in the 2017 sample for a second time in 2018. This applies both in the full sample and in our matched dataset using a bandwidth of 2 months. To address panel attrition, additional refugees were sampled for the 2018 wave of the survey. As a result, the 2018 wave includes about 1,000 new respondents who did not participate in the 2017 wave. About half of the respondents in our 2017 and 2018 matched samples using a two-month bandwidth already participated in the 2016 wave of the SOEP survey (47\% and $50 \%$ respectively).

\section{A.4.2 Survey items}

Among the survey questions we use, the items on the perceived likelihood of finding employment within the next 5 years (2017) and feeling welcome in Germany (2018) were only included in the questionnaire in one survey year. To the best of our knowledge, there was no substantive reason to only include these items in a single survey year. To allow respondents to complete the questionnaire in a reasonable amount of time, some 2017 items were not included in the 2018 wave of the survey.

\section{A.4.3 Information on the asylum decision date}

The information on the asylum decision year and month, which we use to code the treatment assignment, was self-reported. Some SOEP respondents may have looked up the relevant information in their official asylum application documents during the survey interview. Unfortunately, we do not observe whether respondents used their asylum documents to complete the questionnaire or not. We only observe the year and month of the asylum approval date, hence we cannot infer individual identities from the SOEP data. 


\section{A.5 Details on the contribution of the paper}

Broadly, our study adds to a group of studies that analyzes the effect of immigration policies on immigrant outcomes. Examples of relevant prior work are Cobb-Clark (2003); Fleischmann and Dronkers (2010); Dinesen and Hooghe (2010); Tani (2020) and Aksoy, Poutvaara and Schikora (2020). Both Fleischmann and Dronkers (2010) and Dinesen and Hooghe (2010) use data from the European Social Survey to analyze the relationship between country-level variables, such as unemployment rates and the favorability of immigration policies. This approach is advantageous in that it allows for broad geographical coverage. However, it also makes it harder to isolate the effects of the policy from other country-level characteristics, since the variation in policy favorability is observed at the country level. However, country-level immigration policies are highly dependent on the political, social, and economic environment in a given country. In cross-national comparisons, it is very difficult to isolate variation in just the policy environment, while holding other national background variables fixed. Our approach, in contrast, does exactly this - we leverage variation in policy implementation that is determined by a date cutoff within Germany. In doing so, we hold country-level characteristics fixed, but are still able to observe individuals who are or are not affected by a restrictive immigration policy. What is more, the design of the policy makes it possible to also hold constant potentially unobserved individual-level confounding factors, since we expect individuals on either side of the application decision date cutoff to be similar (see section 4 for a detailed discussion of our identification strategy).

Since we examine policy differences within the same country, our study is related to work such as Cobb-Clark (2003) and Tani (2020). These two studies examine changes in immigration policy in Australia during the 1990s, comparing immigrant cohorts before and after the policy changed. The policy change entailed stricter entry requirements for economic migrants, as well as the abolishment of social security benefits and government-sponsored labor market programs. We note that this policy is substantially different from the one we look at - it mainly pertains to entry requirements. In contrast, we examine a policy that affects refugees after they have arrived. As a result, Cobb-Clark (2003) and Tani (2020) primarily provide evidence on policies that restrict 
movement between countries, while our paper sheds light on movement restrictions within the destination country.

While methodologically similar, we argue that our research design improves on the approach taken in these two studies, as our strategy is better able to account for potential confounders, particularly those that change over time. Both Cobb-Clark (2003) and Tani (2020) use the same data set to compare immigrant cohorts that arrived about five years apart, with the policy change occurring approximately halfway between the arrival of the two cohorts. As a result, it is not possible to disentangle the effects of the policy from other contextual factors that change over time. This is also discussed by Cobb-Clark (2003), who notes that simultaneous improvements in labor market conditions during the 1990s could have accounted for changes in immigrant labor market outcomes. Our data set gives us more leverage to deal with this type of confounding. First, we rely on a two-month bandwidth around the cutoff the determines whether the policy is applied, which is significantly smaller than the five-year period that Cobb-Clark (2003) and Tani (2020) use. Second, the main determinant of whether refugees are subject to movement restrictions is not the arrival date, but rather the asylum application date. This allows us to compare unaffected and affected refugees while holding arrival quarter constant. Taken together, our empirical strategy enables us to ensure that other time-varying factors do not obscure the effects of the policy itself.

Finally, our results can inform a growing literature on spatial allocation policies. As an example, Aksoy, Poutvaara and Schikora (2020) show that adverse labor market conditions and lower levels of native support for immigrants on the local level hinder economic and social integration. This study is situated in the same context as ours - the authors leverage the fact that refugees in Germany were generally not able to choose the location they were first assigned to. Related research also exists in other contexts, as exemplified by Damm (2014) or Bratsberg et al. (2020). We first note that our study does not primarily ask whether how local context affects refugee integration - in fact, the data at hand does not permit us to observe precise information on e.g. local unemployment rates, prior immigrant presence, etc. Rather, our analysis focuses on the related question of whether a policy that restricts domestic freedom of movement influences integration. To put it differently, we ask how refugees react to the fact that they are denied one of the basic 
civil liberties, i.e. to freely choose one's place of residence. However, we believe that our results can speak to research on the effects of allocation policies and local context. Based on our findings, the negative effects of adverse locational characteristics might be a persistent phenomenon, as we do not find strong evidence that refugees exhibit pronounced residential mobility even when they are permitted to move around freely. Conversely, our results do not suggest that the effects of locational characteristics on integration are amplified by further policies that restrict residential mobility - restricted and unrestricted refugees are about equally likely to stay at the location they were originally assigned to.

Summarizing the previous discussion, the contribution of our study with respect to prior work is both substantive and methodological. First, our within-country strategy allows us to examine the effect of restrictive migration policies, holding fixed other contextual factors that correlate migration policies - this type of confounding cannot be ruled out by existing cross-country research (see Fleischmann and Dronkers 2010; Dinesen and Hooghe 2010) . Second, prior research that uses similar within-country approaches has focused on policies that affect movement between countries, rather than domestic relocation decisions (see Cobb-Clark 2003; Tani 2020). Third, our study can inform work on local-level determinants of immigration integration (see e.g. Bratsberg et al. 2020; Aksoy, Poutvaara and Schikora 2020). We show that movement restrictions do not significantly alter the probability of relocating, suggesting that the potential adverse effects of initial refugee placement are not amplified by a policy that prohibits refugees to leave unfavorable contexts.

\section{A.6 Initial allocation policies and movement restrictions}

There is growing evidence that the initial spatial allocation of refugees crucially shapes integration trajectories. Examples are Bratsberg et al. (2020), who show that refugees in Norway who are placed on more politically engaged neighborhoods themselves are markedly more likely to turn out to vote themselves. A recent paper by Kuhn and Maxwell (2020) shows that refugees in German who are are settled in counties with relatively more foreign-born residents tend to feel more welcome than refugees in counties where there are few foreign-born residents. In a similar vein, Jaschke, Sardoschau and Tabellini (2020) discuss how refugees in Germany are less successful at integrating 
into the labor market when exogenously allocated to regions where anti-immigrant sentiments are more pronounced. Labor market outcomes have also shown to depend on local economic conditions, as demonstrated by Damm (2014) and Åslund and Rooth (2007). Recognizing the importance of local conditions for refugee integration, Bansak et al. (2018) suggest that refugee integration can be facilitated by implementing initial allocation policies that leverage synergies between the characteristics of refugees and local communities in the host country (see also Acharya, Bansak and Hainmueller 2021).

While prior work on initial allocation policies has focused on the role of local economic and social conditions, we demonstrate how the legal environment of the host country can have a crucial impact on integration trajectories.

In addition, movement restrictions may also increase the impact of initial allocation on integration trajectories, as refugees cannot choose their local context themselves. Damm (2014) discusses this issue directly, and remarks that neighborhood effects may be limited when many refugees relocate soon after arrival. However, if refugees are subject to a policy that prohibits relocation, contextual effects may matter more, as the exposure to the initial local context endures for a relatively longer amount of time when compared to refugees who are free to relocate. This is particularly true to the extent that refugees themselves seek to optimize their integration trajectory: those refugees who think that their integration is hindered by local economic conditions (e.g. because of high unemployment) should be most likely to relocate to a different context. Since the local context has been shown to affect perceptions of belonging in the destination country, political participation, as well as success in the labor market, the reinforcement of contextual effects through movement restriction could potentially affect a relatively large domain of integration outcomes. 


\section{A.7 Summary statistics and details on survey outcomes}

Table A.1: Summary statistics: 2017 matched dataset (2 months bandwidth)

\begin{tabular}{|c|c|c|c|c|c|c|}
\hline Variable & Year & Mean & S.D. & $\mathrm{N}$ & Min & Max \\
\hline \multicolumn{7}{|l|}{ Covariates (binary) } \\
\hline $17-25$ years old & 2017 & 0.20 & 0.40 & 242 & 0 & 1 \\
\hline $26-34$ years old & 2017 & 0.34 & 0.47 & 242 & 0 & 1 \\
\hline 35 - 45 years old & 2017 & 0.38 & 0.49 & 242 & 0 & 1 \\
\hline 46 - 54 years old & 2017 & 0.08 & 0.27 & 242 & 0 & 1 \\
\hline Arrival in 2nd Quarter of 2015 & 2017 & 0.03 & 0.17 & 242 & 0 & 1 \\
\hline Arrival in 3rd Quarter of 2014 & 2017 & 0.02 & 0.13 & 242 & 0 & 1 \\
\hline Arrival in 3rd Quarter of 2015 & 2017 & 0.78 & 0.42 & 242 & 0 & 1 \\
\hline Arrival in 4th Quarter of 2014 & 2017 & 0.01 & 0.09 & 242 & 0 & 1 \\
\hline Arrival in 4th Quarter of 2015 & 2017 & 0.17 & 0.38 & 242 & 0 & 1 \\
\hline Bachelors or equivalent level & 2017 & 0.22 & 0.42 & 242 & 0 & 1 \\
\hline Eritrean & 2017 & 0.01 & 0.09 & 242 & 0 & 1 \\
\hline Female & 2017 & 0.26 & 0.44 & 242 & 0 & 1 \\
\hline Iraqi & 2017 & 0.04 & 0.20 & 242 & 0 & 1 \\
\hline Lower secondary education & 2017 & 0.22 & 0.42 & 242 & 0 & 1 \\
\hline Male & 2017 & 0.74 & 0.44 & 242 & 0 & 1 \\
\hline Movement restriction treatment & 2017 & 0.50 & 0.50 & 242 & 0 & 1 \\
\hline Post-secondary non-tertiary education & 2017 & 0.01 & 0.09 & 242 & 0 & 1 \\
\hline Primary education & 2017 & 0.30 & 0.46 & 242 & 0 & 1 \\
\hline Syrian & 2017 & 0.95 & 0.22 & 242 & 0 & 1 \\
\hline Upper secondary education & 2017 & 0.25 & 0.43 & 242 & 0 & 1 \\
\hline \multicolumn{7}{|l|}{ Outcomes } \\
\hline Contact: co-nationals & 2017 & 4.09 & 1.47 & 242 & 1 & 6 \\
\hline Contact: natives & 2017 & 3.86 & 1.82 & 242 & 1 & 6 \\
\hline Contact: other immigrants & 2017 & 2.92 & 1.85 & 242 & 1 & 6 \\
\hline Employed & 2017 & 0.10 & 0.30 & 242 & 0 & 1 \\
\hline Identification with home country & 2017 & 3.67 & 1.15 & 241 & 1 & 5 \\
\hline Perceived employment prospects & 2017 & 82.99 & 20.52 & 67 & 0 & 100 \\
\hline Social events: culture & 2017 & 1.23 & 0.53 & 241 & 1 & 4 \\
\hline Social events: entertainment & 2017 & 1.42 & 0.77 & 241 & 1 & 4 \\
\hline Social events: going out & 2017 & 2.48 & 1.11 & 242 & 1 & 5 \\
\hline Social events: religious & 2017 & 2.10 & 1.22 & 239 & 1 & 4 \\
\hline Social events: sports & 2017 & 1.59 & 1.02 & 241 & 1 & 5 \\
\hline
\end{tabular}

Note: The table contains summary statistics for all background variables and outcomes. All covariates are binary. In the main analyses, we standardize all outcomes except employment. 
Table A.2: Summary statistics: 2018 matched dataset (2 months bandwidth)

\begin{tabular}{lcccccc}
\hline Variable & Year & Mean & S.D. & N & Min & Max \\
\hline Covariates (binary) & & & & & & \\
17 - 25 years old & 2018 & 0.15 & 0.36 & 208 & 0 & 1 \\
26 - 34 years old & 2018 & 0.36 & 0.48 & 208 & 0 & 1 \\
35 - 45 years old & 2018 & 0.42 & 0.50 & 208 & 0 & 1 \\
46 - 54 years old & 2018 & 0.06 & 0.23 & 208 & 0 & 1 \\
55 - 64 years old & 2018 & 0.01 & 0.10 & 208 & 0 & 1 \\
Afghan & 2018 & 0.01 & 0.10 & 208 & 0 & 1 \\
Arrival in 2nd Quarter of 2015 & 2018 & 0.07 & 0.26 & 208 & 0 & 1 \\
Arrival in 3rd Quarter of 2015 & 2018 & 0.71 & 0.45 & 208 & 0 & 1 \\
Arrival in 4th Quarter of 2015 & 2018 & 0.22 & 0.41 & 208 & 0 & 1 \\
Bachelors or equivalent level & 2018 & 0.24 & 0.43 & 208 & 0 & 1 \\
Female & 2018 & 0.26 & 0.44 & 208 & 0 & 1 \\
Lower secondary education & 2018 & 0.24 & 0.43 & 208 & 0 & 1 \\
Male & 2018 & 0.74 & 0.44 & 208 & 0 & 1 \\
Movement restriction treatment & 2018 & 0.52 & 0.50 & 208 & 0 & 1 \\
Primary education & 2018 & 0.28 & 0.45 & 208 & 0 & 1 \\
Syrian & 2018 & 0.99 & 0.10 & 208 & 0 & 1 \\
Upper secondary education & 2018 & 0.24 & 0.43 & 208 & 0 & 6 \\
Outcomes & & & & & & 6 \\
Contact: co-nationals & 2018 & 4.00 & 1.47 & 207 & 1 & 6 \\
Contact: natives & 2018 & 3.94 & 1.96 & 207 & 1 & 5 \\
Contact: other immigrants & 2018 & 2.98 & 1.90 & 207 & 1 & 5 \\
Employed & 2018 & 0.25 & 0.43 & 208 & 0 & 5 \\
Feel welcome in Germany & 2018 & 4.06 & 0.89 & 194 & 1 & 5 \\
Identification with home country & 2018 & 3.55 & 1.30 & 207 & 1 & 5 \\
Social events: culture & 2018 & 1.29 & 0.57 & 195 & 1 & 5 \\
Social events: entertainment & 2018 & 1.50 & 0.83 & 194 & 1 & 1 \\
Social events: going out & 2018 & 2.74 & 1.07 & 194 & 1 & 1 \\
Social events: religious & 2018 & 1.67 & 1.23 & 12 & 1 & 1 \\
Social events: sports & 2018 & 1.68 & 1.08 & 195 & 1 & 5 \\
\hline
\end{tabular}

Note: The table contains summary statistics for all background variables and outcomes. All covariates are binary. In the main analyses, we standardize all outcomes except employment. 


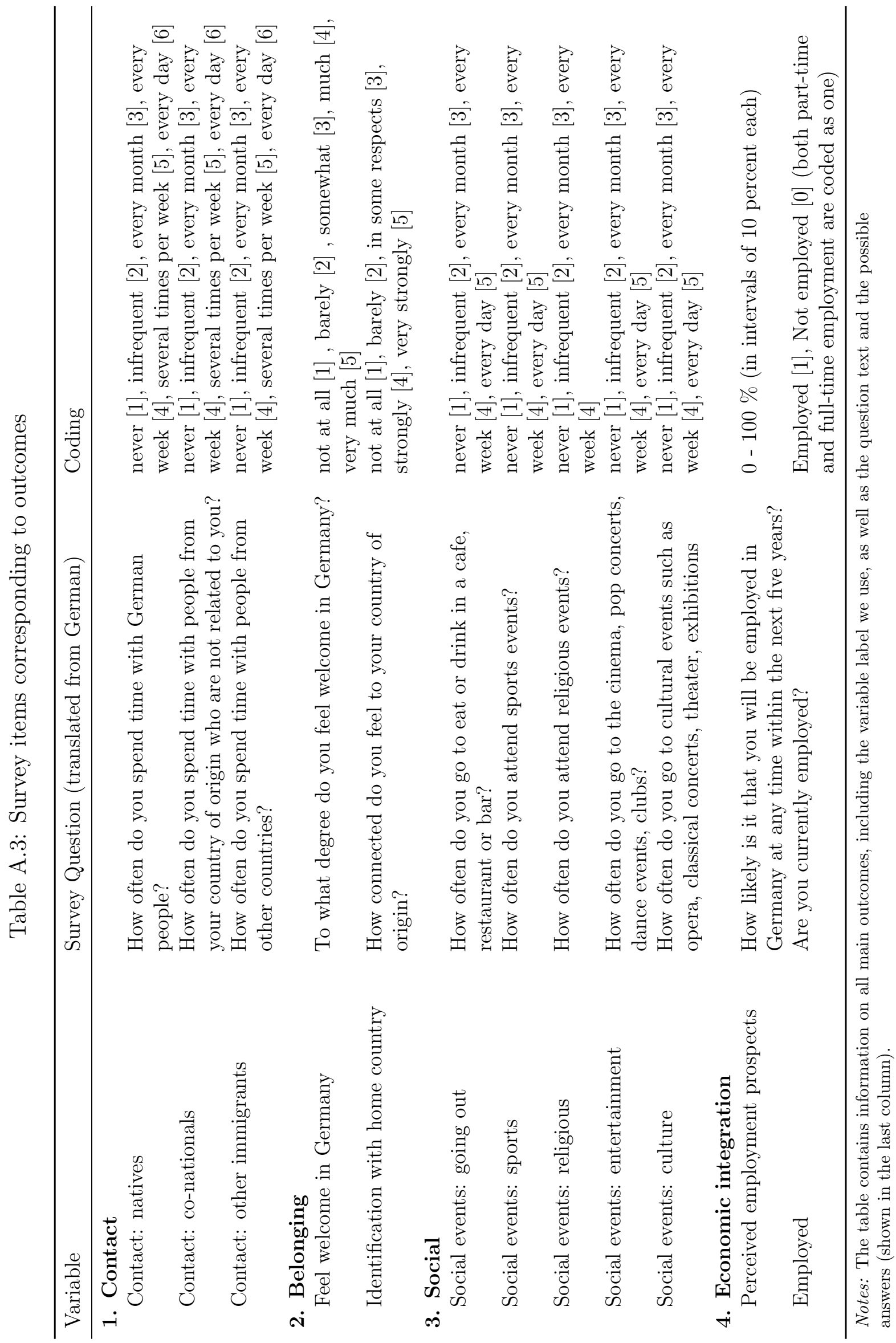




\section{A.8 Pre-treatment covariate balance}

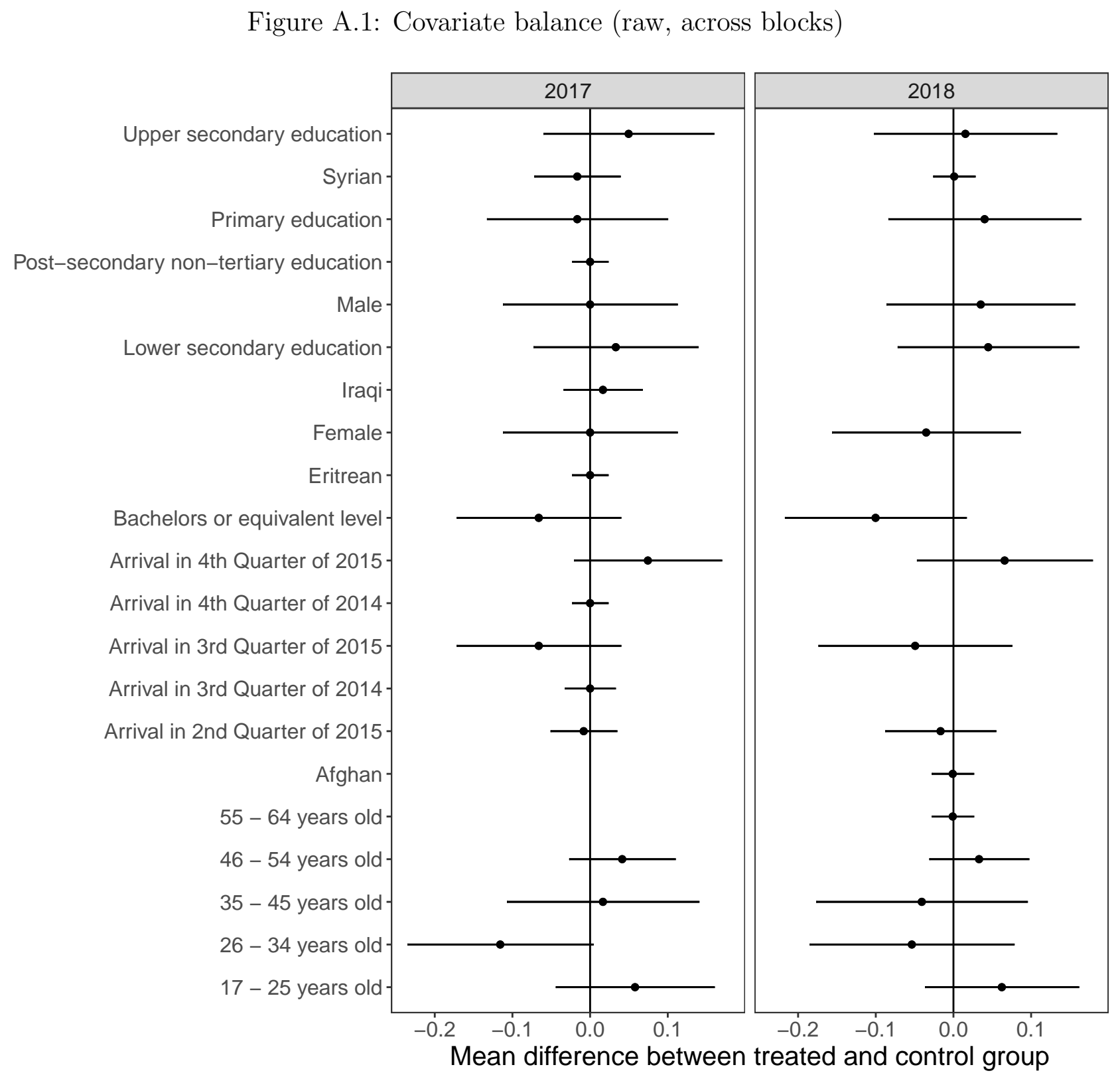

Note: The figure shows the mean difference between the treated and control groups for the sample we use to estimate our main results presented in figure 1. We matched respondents within 2 months around the treatment assignment cutoff. All covariates are binary indicator variables. Some covariate categories are not represented in the matched datasets in either year. For example: for the 2018 sample using a two-month bandwidth, we do not have Iraqi refugees in our matched sample. We emphasize that covariate balance within the covariate blocks described in section 4 is perfect by construction. Comparing the treated and control groups across blocks results in some imbalance because we match each treated unit to all available control units. Because of this, the relative size of the treated and control group can vary across blocks. 


\section{A.9 Average responses by distance to January 2016 cutoff}

Figure A.2: Average response by distance to cutoff - contact outcomes

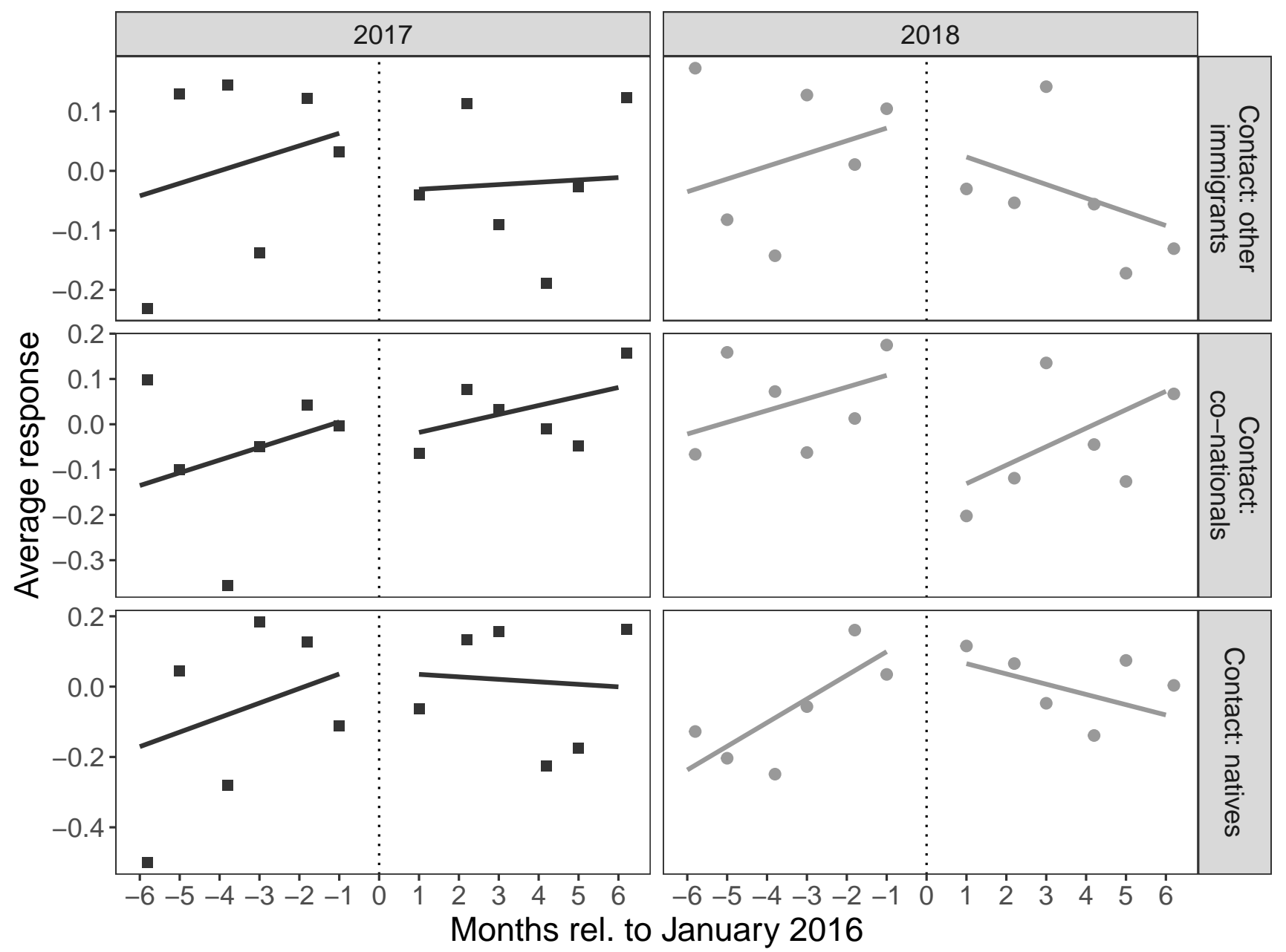

Notes: The figure shows the average response conditional on the month relative to the January 2016 cutoff. Positive values on the $\mathrm{x}$-axis indicate months after the cutoff, such that 1 equals January 2016, while negative values indicate months prior to the cutoff. All outcomes are standardized such that the mean is zero and standard deviation is one. 
Figure A.3: Average response by distance to cutoff - contact outcomes

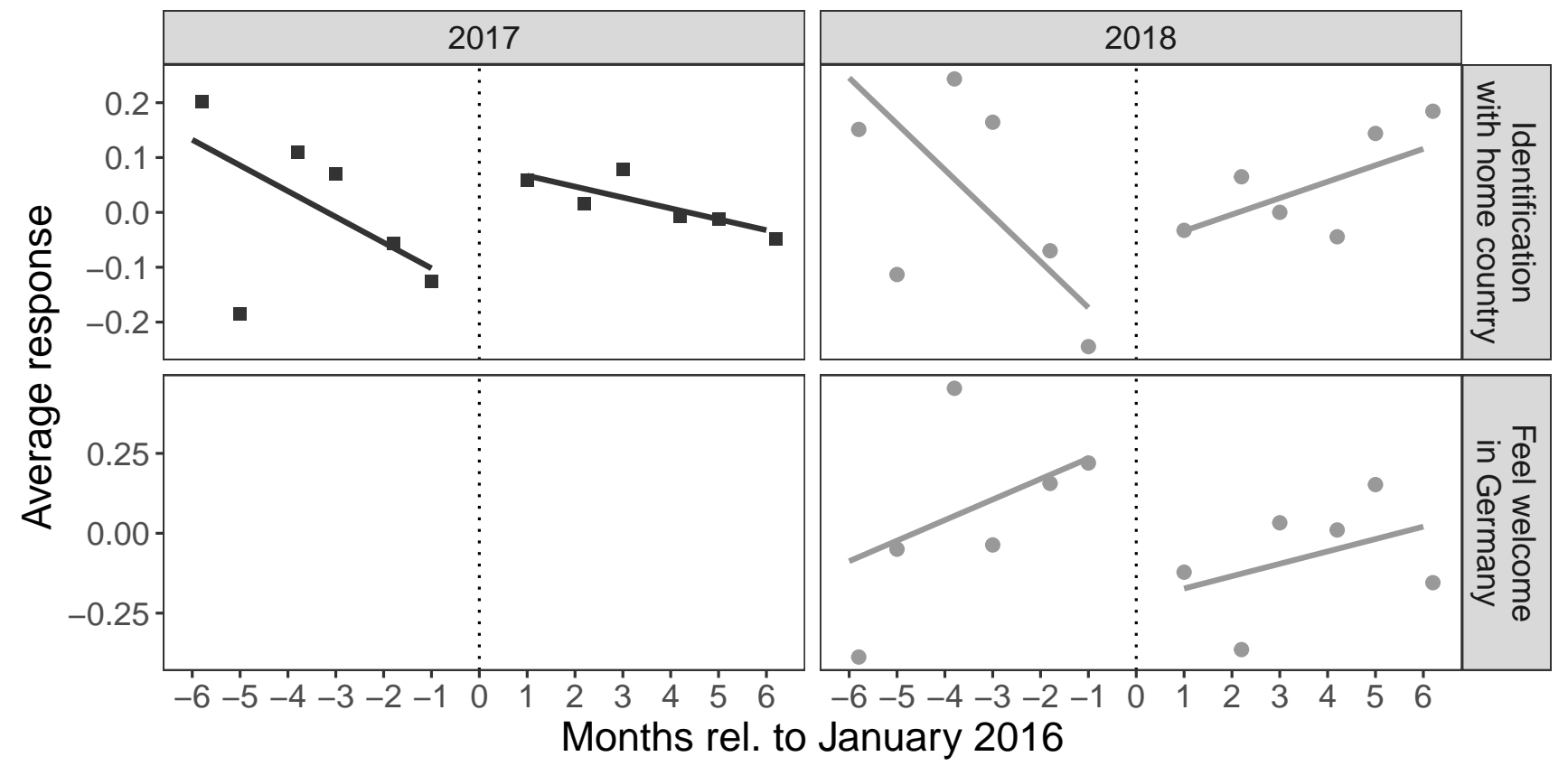

Notes: The figure shows the average response conditional on the month relative to the January 2016 cutoff. Positive values on the $\mathrm{x}$-axis indicate months after the cutoff, such that 1 equals January 2016, while negative values indicate months prior to the cutoff. All outcomes are standardized such that the mean is zero and standard deviation is one. 
Figure A.4: Average response by distance to cutoff - contact outcomes

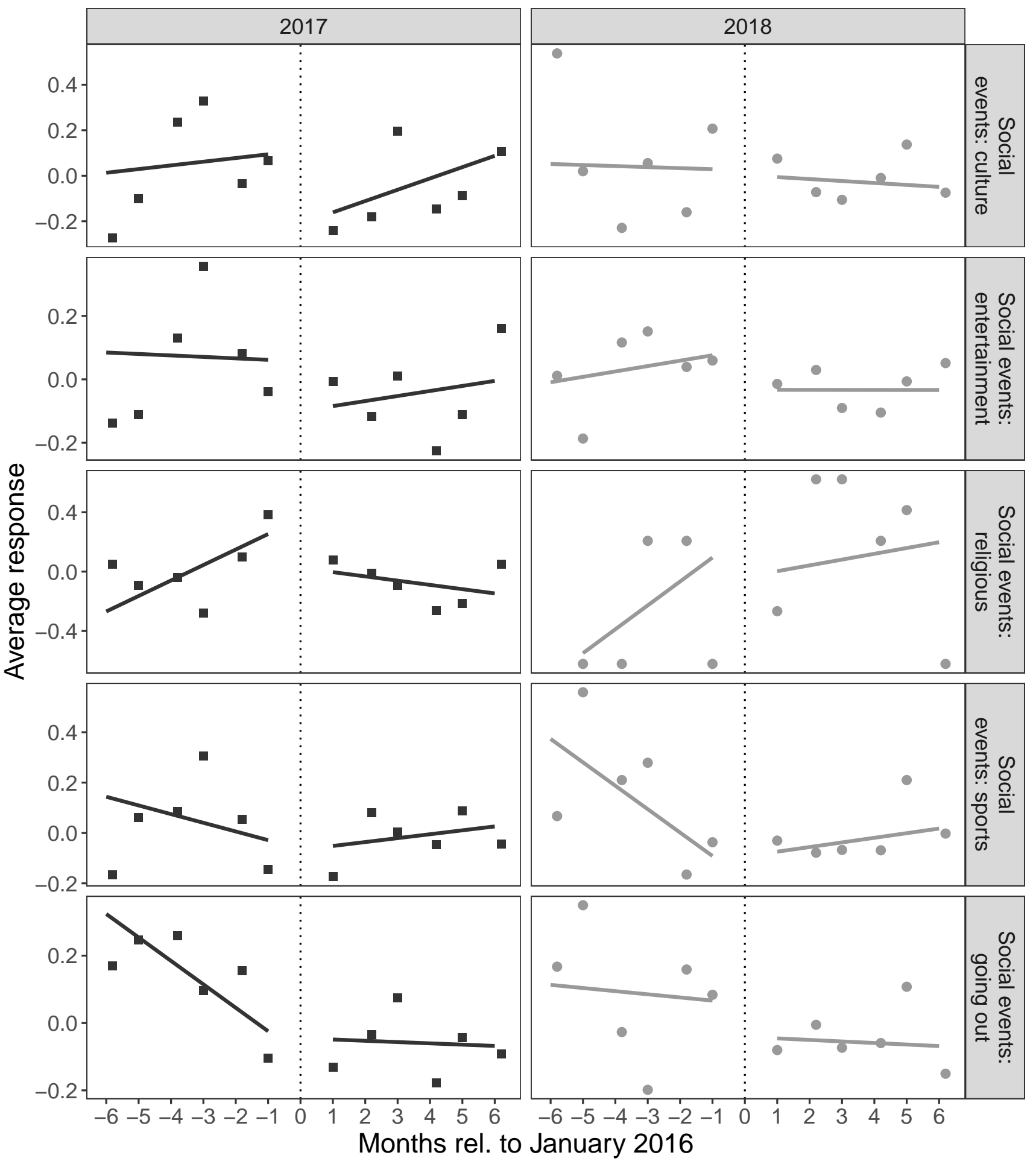

Notes: The figure shows the average response conditional on the month relative to the January 2016 cutoff. Positive values on the $\mathrm{x}$-axis indicate months after the cutoff, such that 1 equals January 2016, while negative values indicate months prior to the cutoff. All outcomes are standardized such that the mean is zero and standard deviation is one. 
Figure A.5: Average response by distance to cutoff - contact outcomes

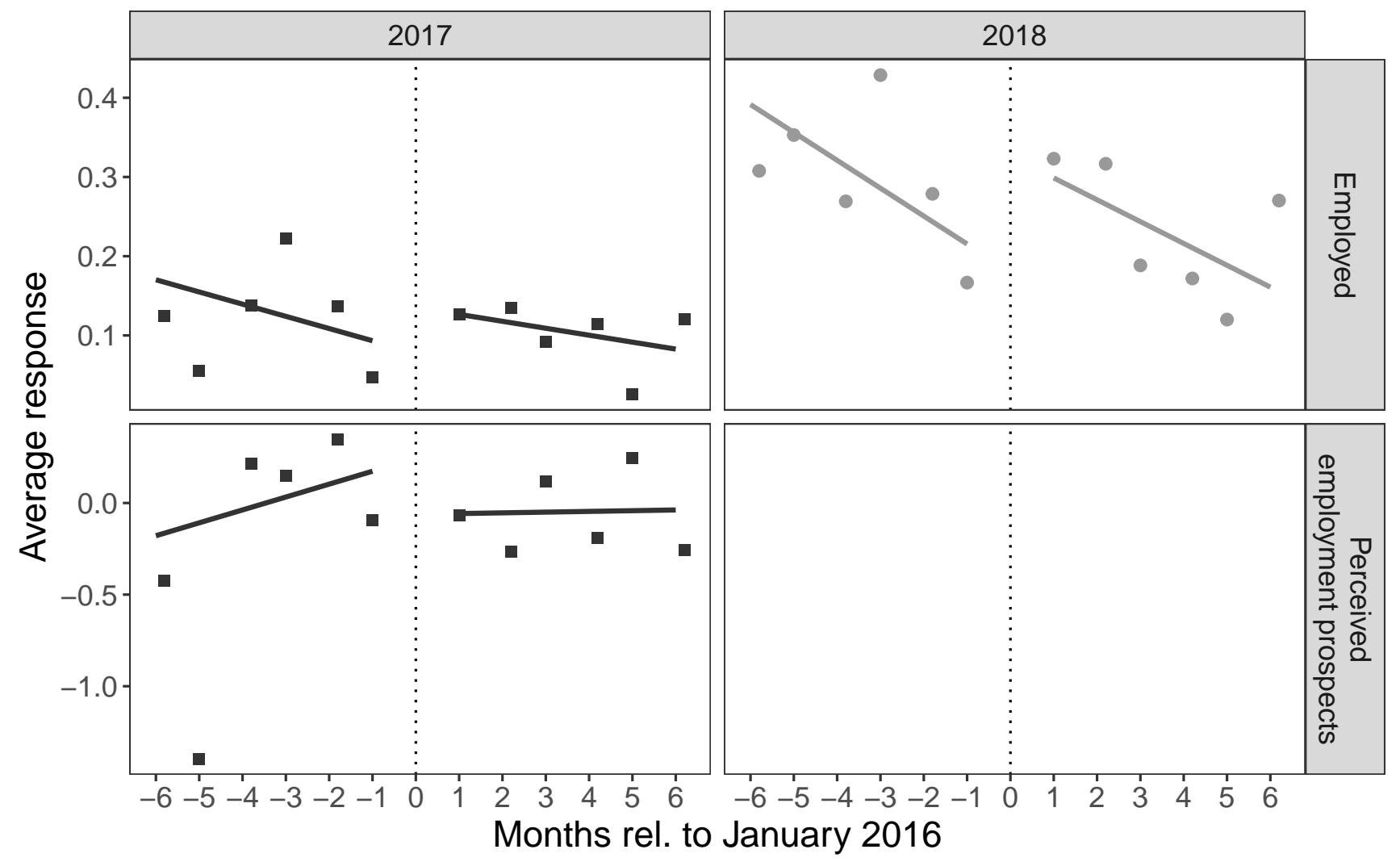

Notes: The figure shows the average response conditional on the month relative to the January 2016 cutoff. Positive values on the $\mathrm{x}$-axis indicate months after the cutoff, such that 1 equals January 2016, while negative values indicate months prior to the cutoff. Employment prospects are standardized, while the employment indicator is binary. 


\section{A.10 Movement within Germany conditional on asylum approval date}

Figure A.6: Movement within Germany

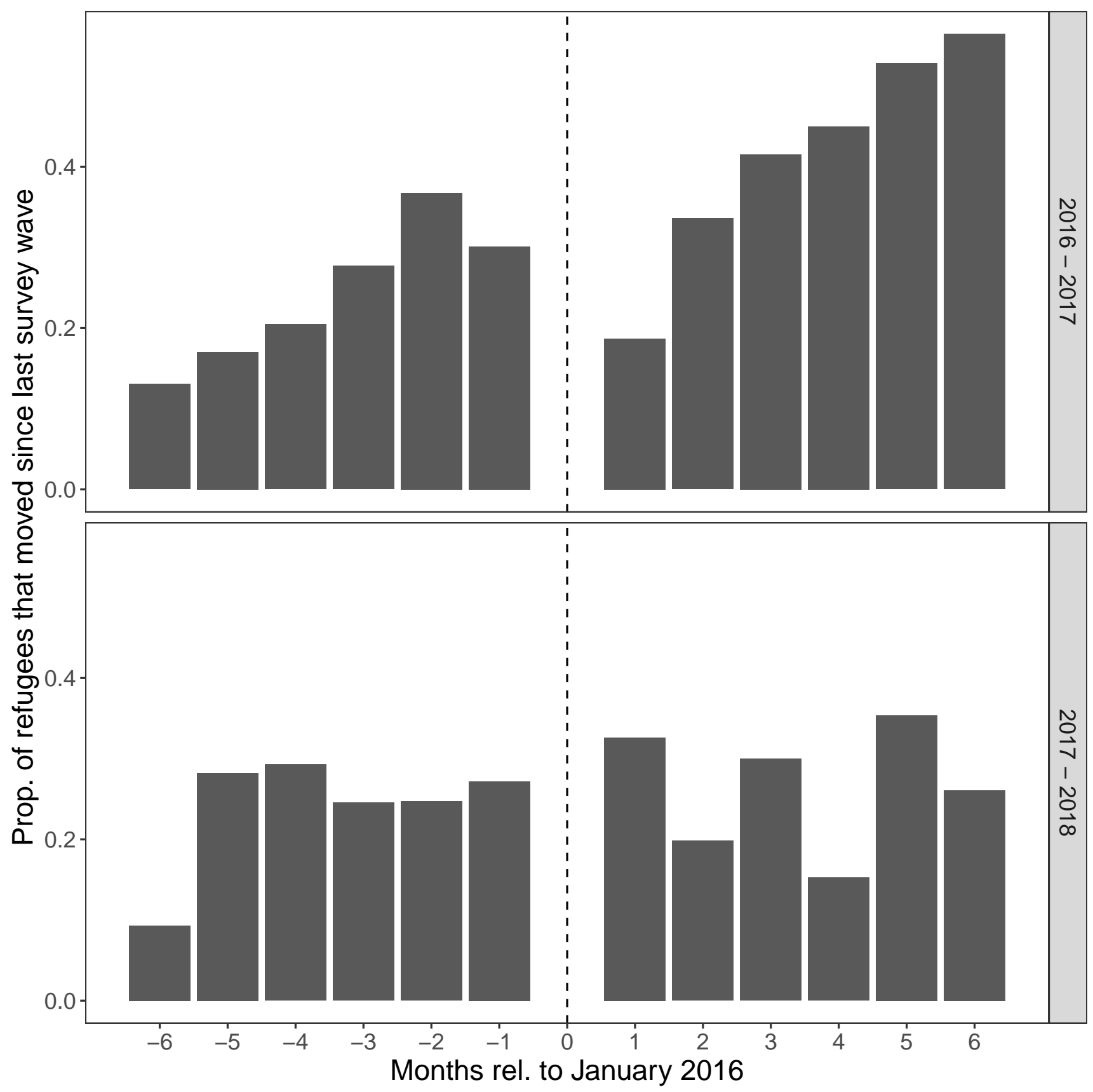

Note: The figure shows the relative frequency of refugees who changed their place of residence between the 2016/2017 and 2017/2018 survey waves, grouped by months around the January 1, 2016 cutoff. The survey item we use asks respondents whether they reside at the same address as in the previous survey wave. We are not able to distinguish between movement across or within counties in this analysis. We also do not observe the county that refugees were initially assigned to after arrival in Germany. 


\section{A.11 Effect on relocations within Germany}

Our data does not allow us to perfectly reconstruct the movement history of refugees after their initial assignment. However, we do observe whether refugees moved between survey waves and whether they live in urban or rural areas.

As reported in the main body of the paper, we do not find statistically significant differences in the propensity to move between restricted and unrestricted refugees (see figure A.7). Why do movement restrictions have little impact on relocation decisions? Additional restrictions during the asylum decision process and the relatively high cost of relocating may account for this finding. All refugees are prohibited from relocating until their asylum application is approved.7 During the often lengthy asylum application process, refugees may have become accustomed to life at the initial assignment location, increasing the cost of relocation after they are permitted to do so. As a result, refugees may find it more convenient to remain at the location they were originally assigned to, even if they are permitted to move. This would suggest a rather low baseline propensity of refugees to move after the initial random assignment to a location. While likely not precisely equal to zero, the treatment effect of the restriction on movement is likely of small magnitude.

Table A.4: Duration since entry and movement restrictions

\begin{tabular}{lcrr}
\hline Treatment status & Year & $\begin{array}{r}\text { Avg. time spent in } \\
\text { DE (years) }\end{array}$ & $\begin{array}{r}\text { Avg. time since } \\
\text { restrictions (years) }\end{array}$ \\
\hline Not restricted & 2017 & 1.93 & 0.91 \\
Restricted & 2017 & 1.98 & 0.98 \\
Not restricted & 2018 & 3.06 & 2.05 \\
Restricted & 2018 & 3.13 & 2.14 \\
\hline
\end{tabular}

Note: The table shows how long, on average, respondents have lived in Germany when the SOEP survey was conducted. In addition, the table contains the time that has passed between the August 2016, when restrictions were first applied, and the date when survey data was collected. We show both statistics conditional on respondent restriction status.

\footnotetext{
${ }^{7}$ Movement restrictions during the asylum application process ('Residenzpflicht') generally apply for up to three months after arrival in Germany.
} 
Figure A.7: Effect of movement restrictions on relocating and likelihood of living in an urban region

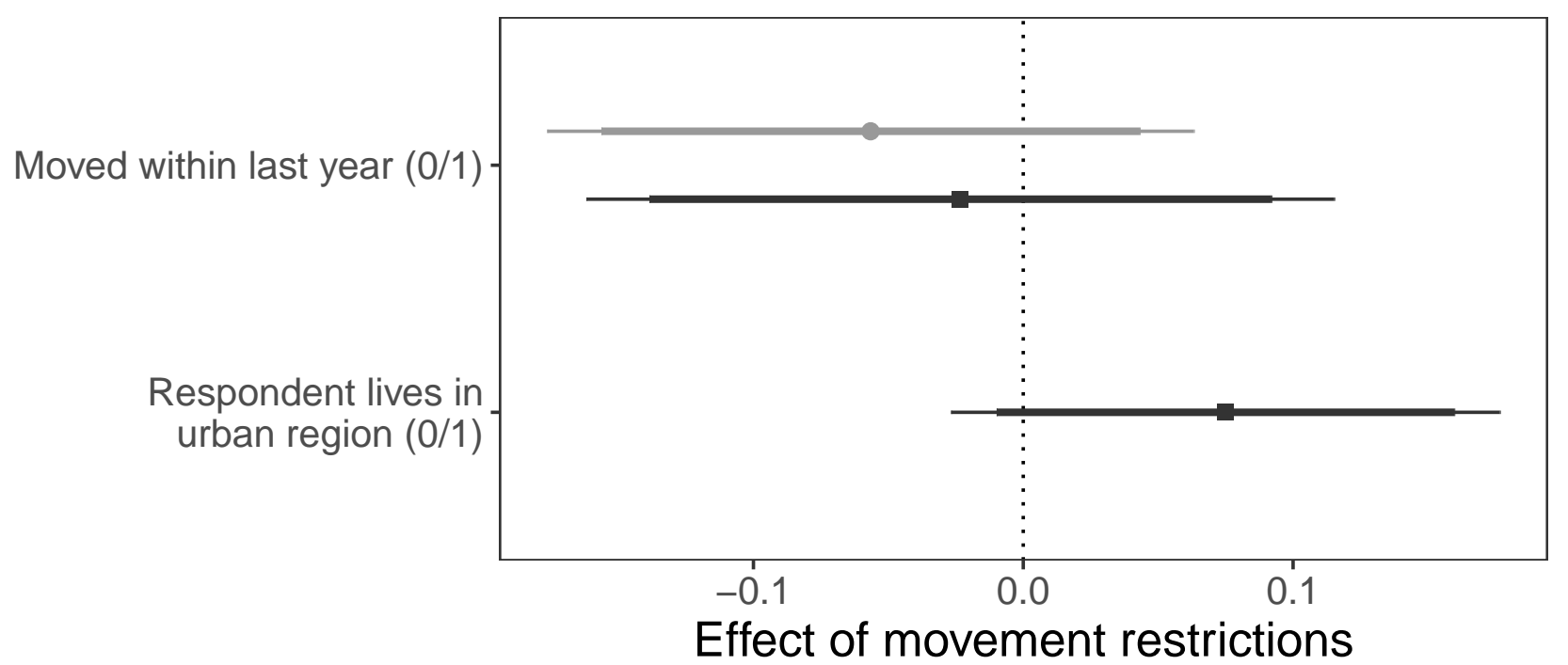

$\rightarrow$ Surveyed in $2017 \multimap$ Surveyed in 2018

Note: The figure shows estimated effects of being subject to movement restrictions on (i) whether respondents moved since the last survey wave and (ii) whether a respondent lives in an 'urban' area. Both outcomes are binary. The SOEP uses the urban/rural definition of the Federal Institute for Research on Building, Urban Affairs, and Spatial Development (BBSR). The item asking whether respondents live in urban areas was only asked in the 2017 survey wave. The horizontal bars represent 90\% (thick lines) / 95\% (thin lines) confidence intervals. 


\section{A.12 Detailed main results}

Table A.5: Main results

\begin{tabular}{lcrllll}
\hline Outcome & Year & Estimate & SE & P & P (RI) & N \\
\hline 1. Contact & & & & & & \\
Contact: natives & 2017 & -0.02 & 0.12 & 0.88 & 0.90 & 242 \\
Contact: natives & 2018 & -0.06 & 0.13 & 0.64 & 0.68 & 207 \\
Contact: co-nationals & 2017 & 0.01 & 0.12 & 0.91 & 0.92 & 242 \\
$\quad$ Contact: co-nationals & 2018 & -0.12 & 0.12 & 0.29 & 0.32 & 207 \\
$\quad$ Contact: other immigrants & 2017 & -0.06 & 0.13 & 0.66 & 0.72 & 242 \\
$\quad$ Contact: other immigrants & 2018 & -0.13 & 0.13 & 0.31 & 0.38 & 207 \\
2. Belonging & & & & & & \\
Feel welcome in Germany & 2018 & -0.46 & 0.12 & 0.00 & 0.00 & 194 \\
Identification with home country & 2017 & 0.23 & 0.13 & 0.08 & 0.13 & 241 \\
Identification with home country & 2018 & 0.39 & 0.13 & 0.00 & 0.01 & 207 \\
3. Social & & & & & & \\
$\quad$ Social events: going out & 2017 & -0.22 & 0.12 & 0.07 & 0.10 & 242 \\
$\quad$ Social events: going out & 2018 & 0.04 & 0.13 & 0.77 & 0.79 & 194 \\
$\quad$ Social events: sports & 2017 & -0.09 & 0.12 & 0.46 & 0.53 & 241 \\
$\quad$ Social events: sports & 2018 & 0.03 & 0.14 & 0.81 & 0.83 & 195 \\
$\quad$ Social events: religious & 2017 & -0.22 & 0.12 & 0.06 & 0.10 & 239 \\
$\quad$ Social events: entertainment & 2017 & -0.20 & 0.12 & 0.09 & 0.13 & 241 \\
$\quad$ Social events: entertainment & 2018 & -0.10 & 0.14 & 0.49 & 0.56 & 194 \\
$\quad$ Social events: culture & 2017 & -0.33 & 0.11 & 0.00 & 0.01 & 241 \\
$\quad$ Social events: culture & 2018 & 0.00 & 0.13 & 0.98 & 0.98 & 195 \\
4. Economic integration & & & & & & \\
$\quad$ Perceived employment prospects & 2017 & -0.61 & 0.26 & 0.02 & 0.08 & 67 \\
$\quad$ Employed & 2017 & 0.03 & 0.04 & 0.40 & 0.46 & 242 \\
Employed & 2018 & 0.15 & 0.05 & 0.00 & 0.01 & 208 \\
\hline
\end{tabular}

The table shows the main results discussed in the text. All outcomes except employment are standardized. 


\section{A.13 Robustness}

Our identification strategy requires that the exact timing of approval decisions around the January 1 cutoff is uncorrelated with unobserved individual or institutional characteristics. However, faster decisions may correlate with more efficient local institutions, which in turn may affect integration. In addition, individual characteristics could affect how quickly decisions are made, although we are unaware of any systematic or anecdotal evidence that this is the case. We also emphasize that more than $90 \%$ of refugees in our sample are Syrians, for whom asylum approval was virtually guaranteed during the study period.

We conduct four supplementary analyses to verify that asylum decision speed is not correlated with integration outcomes independent of its effect on movement restrictions. First, we use the full sample of all refugees and regress the integration outcomes on the duration between the date of arrival and the date of approval. Akin to the main specification, we compare refugees whose asylum applications were approved within four-month intervals. If faster decisions are correlated with individual or institutional characteristics, we would expect to find differences between refugees with earlier and later decisions. We estimate OLS models with block fixed effects, separately for 2017 and 2018. The blocks are defined by the base covariates as well as the application decision time in intervals of four months. As a result, we compare refugees with similar background characteristics whose asylum applications were processed at most four months apart. similar to the two-month bandwidth used in the main analysis. In figure A.21 in the SI, we demonstrate that slightly faster asylum decisions (i.e. at most four months difference) do generally not correlate with integration outcomes.

In a second step, we utilize the panel structure of the SOEP to test for pre-treatment differences between restricted and unrestricted refugees. In doing so, we re-estimate the main specification in figure 1 using outcomes measured in 2016 8 If approval decision timing rather than movement

\footnotetext{
${ }^{8}$ We can only conduct this analysis for a subset of outcomes, as some items were only included in later waves of the survey. The movement restriction went into effect in August 2016. We consider the year 2016 pre-treatment as most SOEP-interviews are conducted over the summer. In addition, the implementation of the law within the states was often delayed by several months.
} 
restrictions affects integration, we would expect to find significant differences in this analysis. Reassuringly, we do not find significant differences between restricted and unrestricted refugees before the policy took effect (see figure A.18 in the SI).

Third, we demonstrate that there are no differences between restricted and unrestricted refugees in terms of pre-migration characteristics. Specifically, we examine balance on social connections to Germany, German language skills, life satisfaction, and traumatic experiences during the migration journey. We present the results from this analysis in figure A.20. We do not find significant differences between restricted and unrestricted refugees for any of the covariates. Prior to their arrival in Germany, treated and untreated refugees were statistically indistinguishable.

Fourth, we demonstrate that asylum decision speed is not determined by pre-migration characteristics such as prior knowledge of the German language. Similar to the analysis shown in figure A.21, we use the full sample of all refugees and regress the asylum decision duration (in months) on a set of pre-migration covariates. Our covariates measure i) German language knowledge before arrival, ii) contacts in Germany before arrival, iii) life satisfaction prior to migration, and iv) traumatic experiences during the migration journey, prior to arrival in Germany. More details on the survey items are provided in section A.13.11. We estimate OLS models with block fixed effects, separately for 2017 and 2018. The blocks are defined by the base covariates as well as the application decision time in intervals of four months. We present the results in figure A.22. We find no statistically significant relationship between any of the pre-migration covariates and slightly faster asylum decision times.

Taken together, the four supplemental analyses provide strong evidence in support of our identification assumptions. In particular, we find no evidence that slightly faster asylum decisions directly affect integration, other than through their effect on movement restrictions.

We conduct eight additional robustness checks to ensure that our results are not driven by the choice of specification, sample, covariates or unobserved confounding.

First, we show the average responses in the full sample for each outcome, for a bandwidth of 6 months around the treatment assignment cutoff in figures A.2, A.3, A.4, and A.5 in the SI. Next, we present all main results without covariate block fixed effects (see figure A.8 in the 
SI). We also estimate a specification where instead of covariate block fixed effects, we directly include the covariates as control variables in the model (see figure A.9). To further ensure that our results are not driven by the set of covariates we chose, we also estimate specifications where we sequentially omit one of the five covariates for the exact matching and to construct covariate blocks (see figure A.10). We find that our results remain unchanged when compared to figure 1 . Second, we present the results for varying bandwidths around the January 1 cutoff, using the same matching procedure as described in section 4 . In figures A.12 and A.13 in the SI, we show that our results are largely robust to varying the bandwidth. We observe that effects are generally stronger for smaller bandwidths, where the assumption of no unobserved confounding is more likely to hold.

Third, we conduct randomization inference by creating 1,000 random permutations of the treatment assignment vector within covariate blocks. We then re-estimate the results presented in figure 1. In figures A.14 and A.15, we present the resulting distributions of the t-statistic for the treatment effect estimates across 1,000 permutations. We show the corresponding two-sided p-values in table A.5 in the SI. We find that the resulting p-values are similar to the ones obtained from the base specifications.

Fourth, we estimated pooled models, where we do not estimate separate effects for the 2017 and 2018 survey waves. Rather, we pool both waves, adding block* year fixed effects and standard errors clustered by respondent. We again find negative effects on both belonging and social engagement (see figure A.16 in the SI).

Fifth, we estimate a series of regression discontinuity models as an alternative to the main specification described in section 4. In doing so, we use months relative to the January 2016 threshold as the running variable, and then estimate the change in levels of the outcomes around the threshold. We present the results in section A.13.8 in the SI. We find that the regression discontinuity results are generally very similar to our main results in figure 1, and therefore confirm our findings.

Sixth, we subset the sample to Syrians, which make up more than $90 \%$ of all respondents in 2017 and 2018. We present the results in figure A.19. We observe that the results using this 
alternative sample are very similar to our main results presented in figure 1.

Seventh, we demonstrate that our results are robust to alternative parameter choices in the matching procedure. We estimate a specification where we use one-to-one nearest neighbor propensity score matching. To break ties between potential control units, we now include age as a continuous rather than discrete covariate. We present the results from this analysis in figure A.11 in the SI. Our main results remain unchanged when using one-to-one instead of one-to-many matching. Eighth, we examine the effect of the movement restriction policy on additional outcomes including German language acquisition, integration course participation and interest in contact with Germans. We present the results in figure A.27. We do not find evidence that the movement restriction affected these outcomes. 


\section{A.13.1 Omitting block FEs}

Figure A.8: Effect of movement restrictions, OLS without block FE

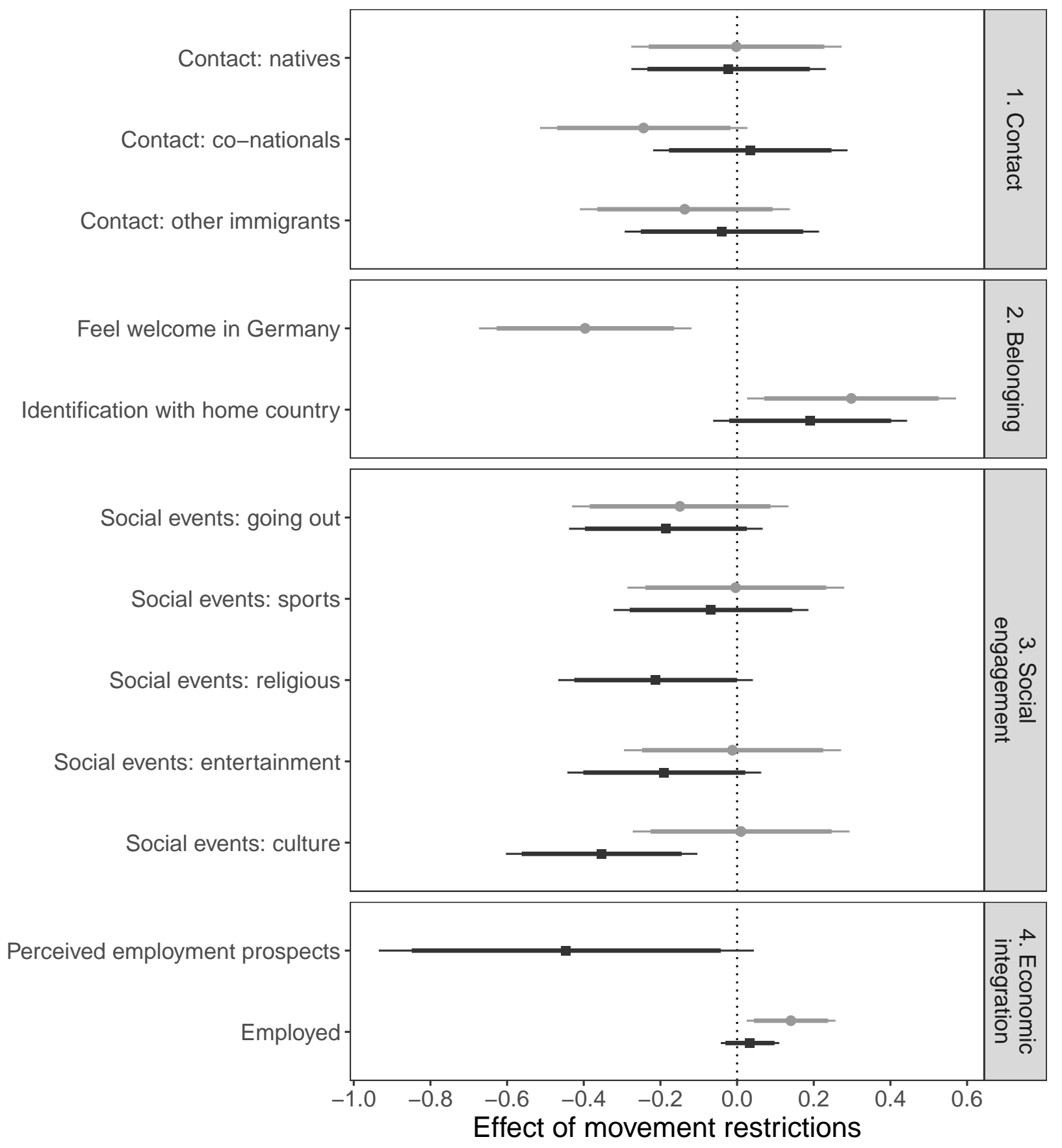

$\because$ Surveyed in $2017 \multimap$ Surveyed in 2018

Note: The figure shows estimated effects of being subject to movement restrictions on the outcomes listed on the left-hand side. The horizontal bars represent 90\% (thick lines) / 95\% (thin lines) confidence intervals. All variables are standardized except employment status. 


\section{A.13.2 Controlling for covariates instead of block FEs}

Figure A.9: Effect of movement restrictions, OLS including covariates, without block FE

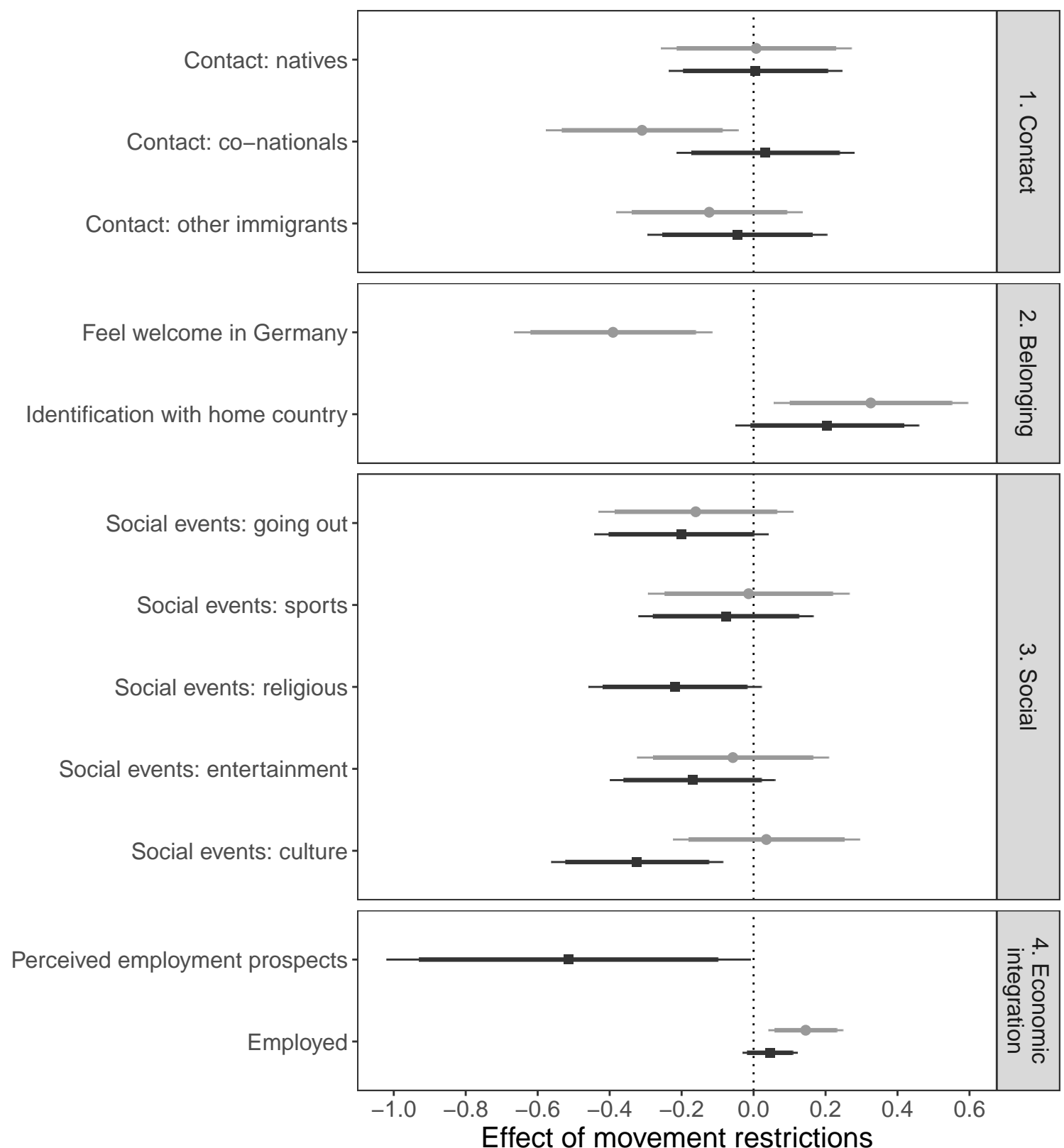

Effect of movement restrictions

$\rightarrow$ Surveyed in $2017 \multimap$ Surveyed in 2018

Note: The figure shows estimated effects of being subject to movement restrictions on the outcomes listed on the left-hand side. The horizontal bars represent 90\% (thick lines) / 95\% (thin lines) confidence intervals. All variables are standardized except employment status. We repeat the same matching procedure and analysis as for our main results with one difference: instead of fixed effects for covariate blocks, we directly include the covariates in the OLS model as control variables. 


\section{A.13.3 Omitting selected covariates}

Figure A.10: Effect of movement restrictions for different covariate sets

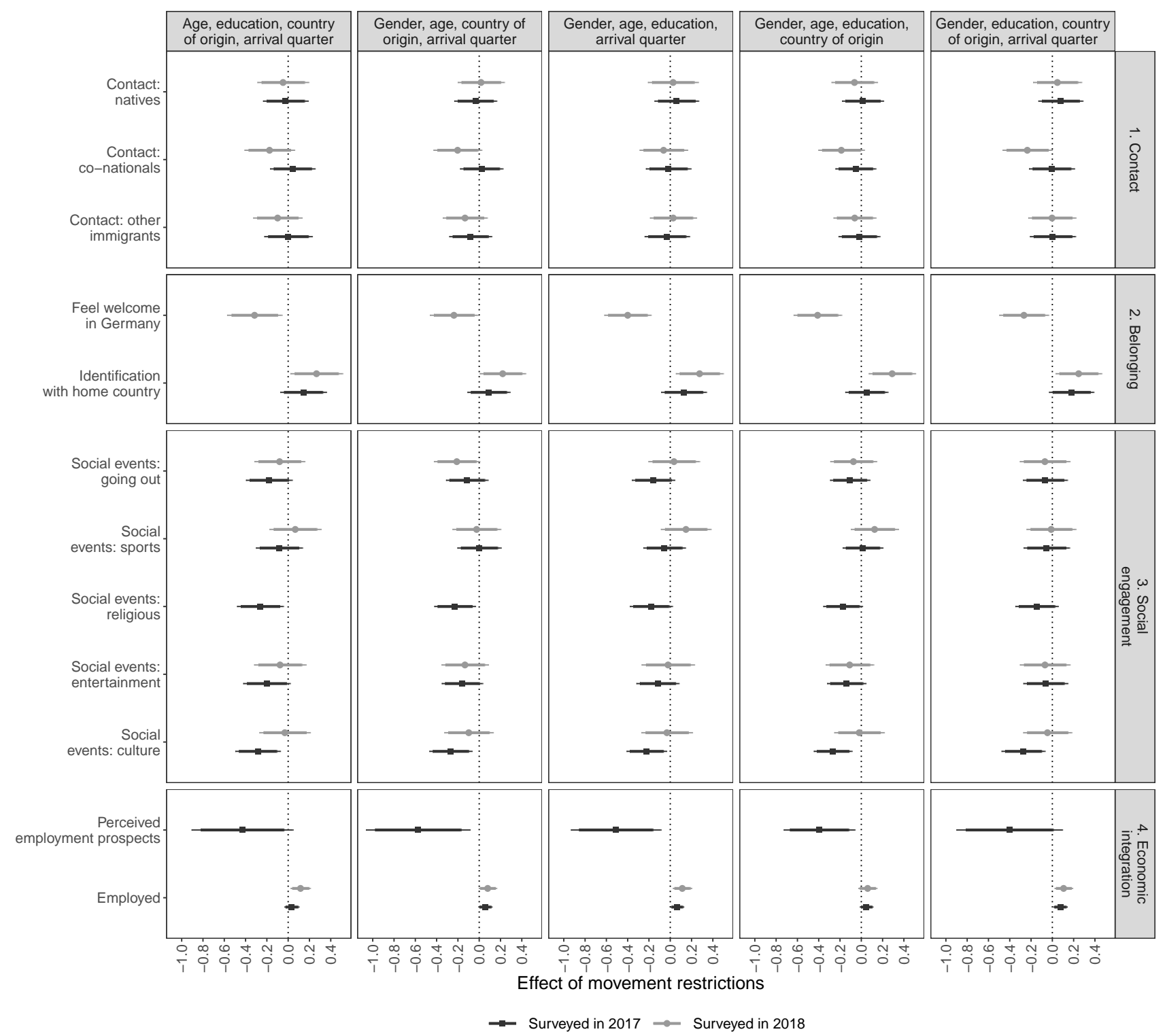

Note: The figure shows estimated effects of being subject to movement restrictions on the outcomes listed on the left-hand side. The horizontal bars represent 90\% (thick lines) / 95\% (thin lines) confidence intervals. All variables are standardized except employment status. We repeat the same matching procedure and analysis as for our main results, but sequentially omit one of the five covariates for exact matching and to construct covariate blocks. Each column corresponds to blocks constructed by using the set of covariates indicated in the facet label. We include covariate block fixed effects in all analyses. 


\section{A.13.4 Results based on one-to-one matching}

Figure A.11: Effect of movement restrictions, based on one-to-one matching

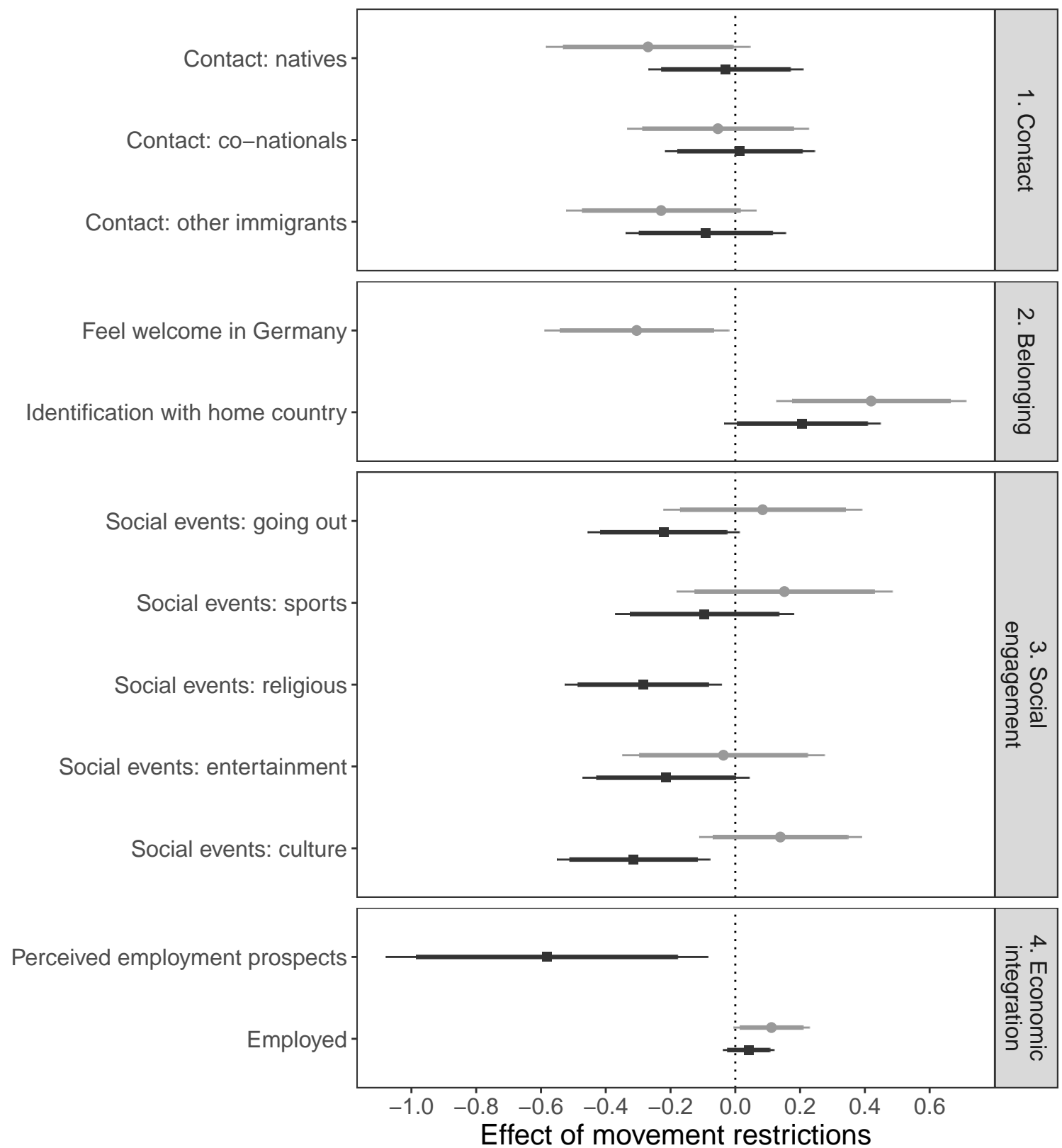

$\rightarrow$ Surveyed in $2017 \rightarrow$ Surveyed in 2018

Note: The figure shows estimated effects of being subject to movement restrictions on the outcomes listed on the left-hand side. The horizontal bars represent 90\% (thick lines) / 95\% (thin lines) confidence intervals. All variables are standardized except employment status. We repeat the same matching procedure and analysis, but use one-to-one nearest neighbor propensity score matching instead. For this analysis, we include age as a continuous covariate. 


\section{A.13.5 Bandwidth sensitivity}

Figure A.12: Bandwidth sensitivity, contact and sense of belonging
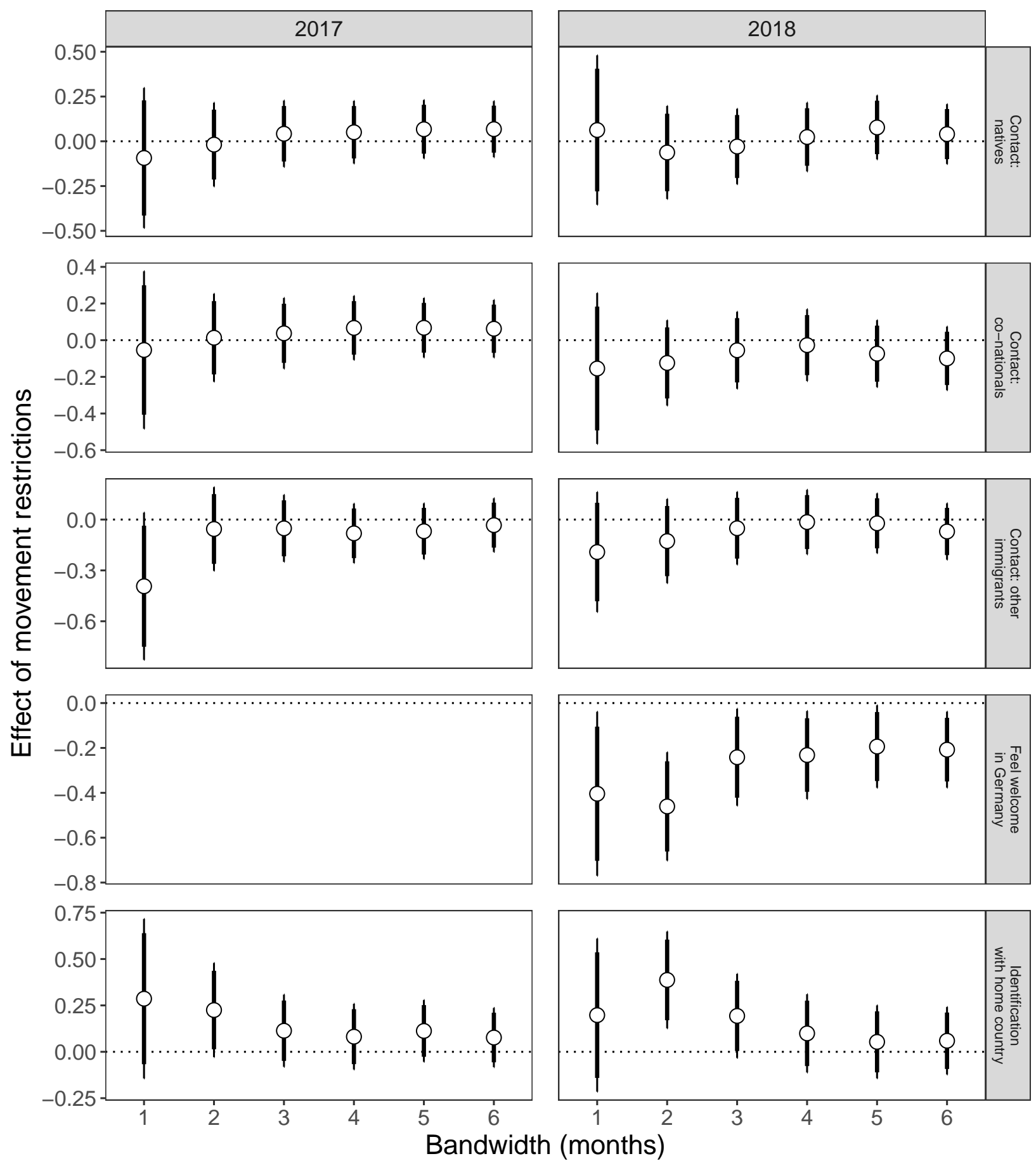

Note: The figure shows estimated effects of being subject to movement restrictions, conditional on bandwidth around the asylum application date cutoff and year when the survey was conducted. The horizontal bars represent 90\% (thick lines) / 95\% (thin lines) confidence intervals. All models include block fixed effects. In cases where we show no estimates, fewer than 20 individuals responded to the survey question, which means we did not estimate a model for the given year-bandwidth combination. 
Figure A.13: Bandwidth sensitivity, social and economic integration
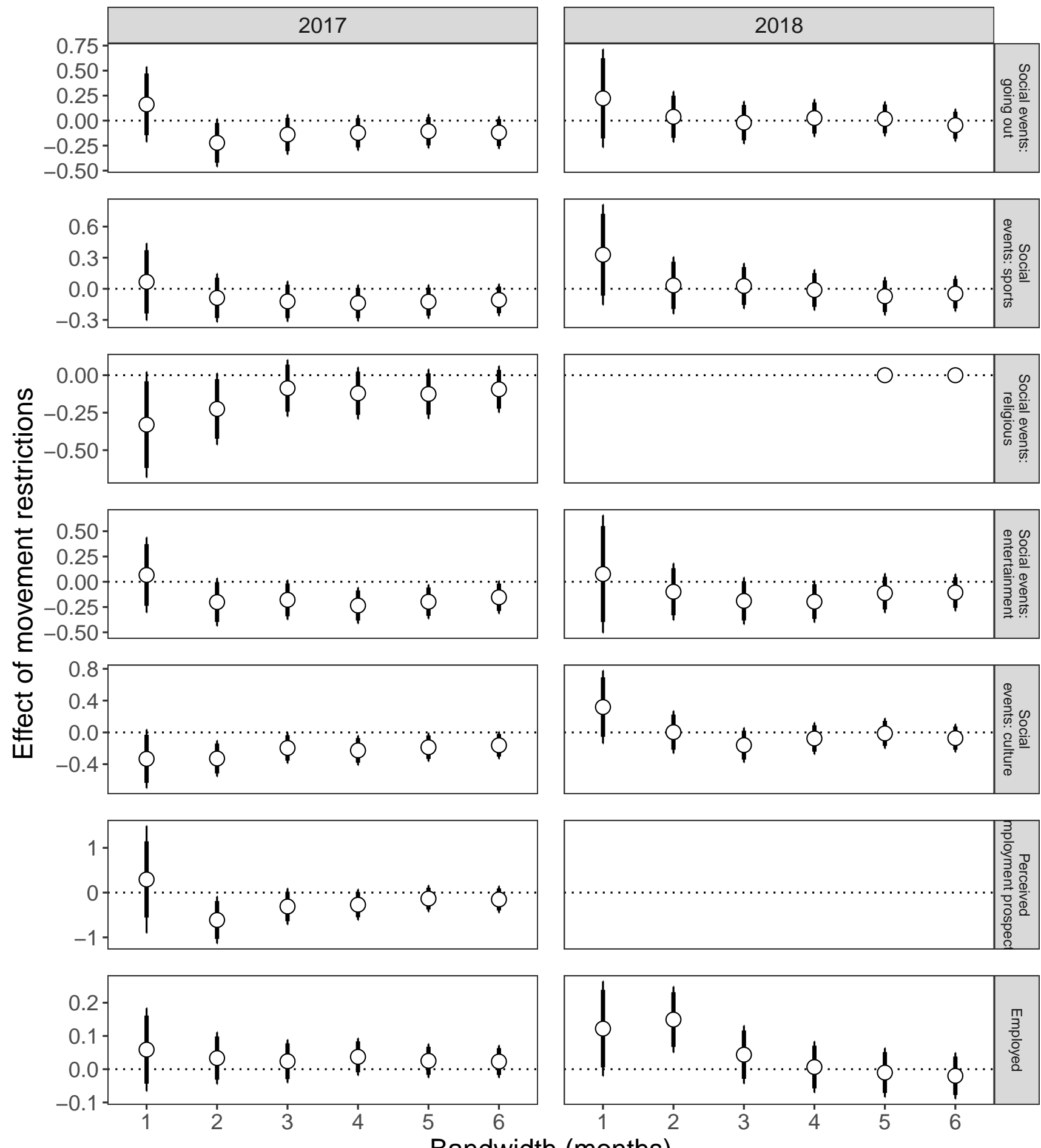

Bandwidth (months)

Note: The figure shows estimated effects of being subject to movement restrictions, conditional on bandwidth around the asylum application date cutoff and year when the survey was conducted. The horizontal bars represent 90\% (thick lines) / 95\% (thin lines) confidence intervals. All models include block fixed effects. In cases where we show no estimates, fewer than 20 individuals responded to the survey question, which means we did not estimate a model for the given year-bandwidth combination. 


\section{A.13.6 Randomization inference}

Figure A.14: Randomization inference, 2017
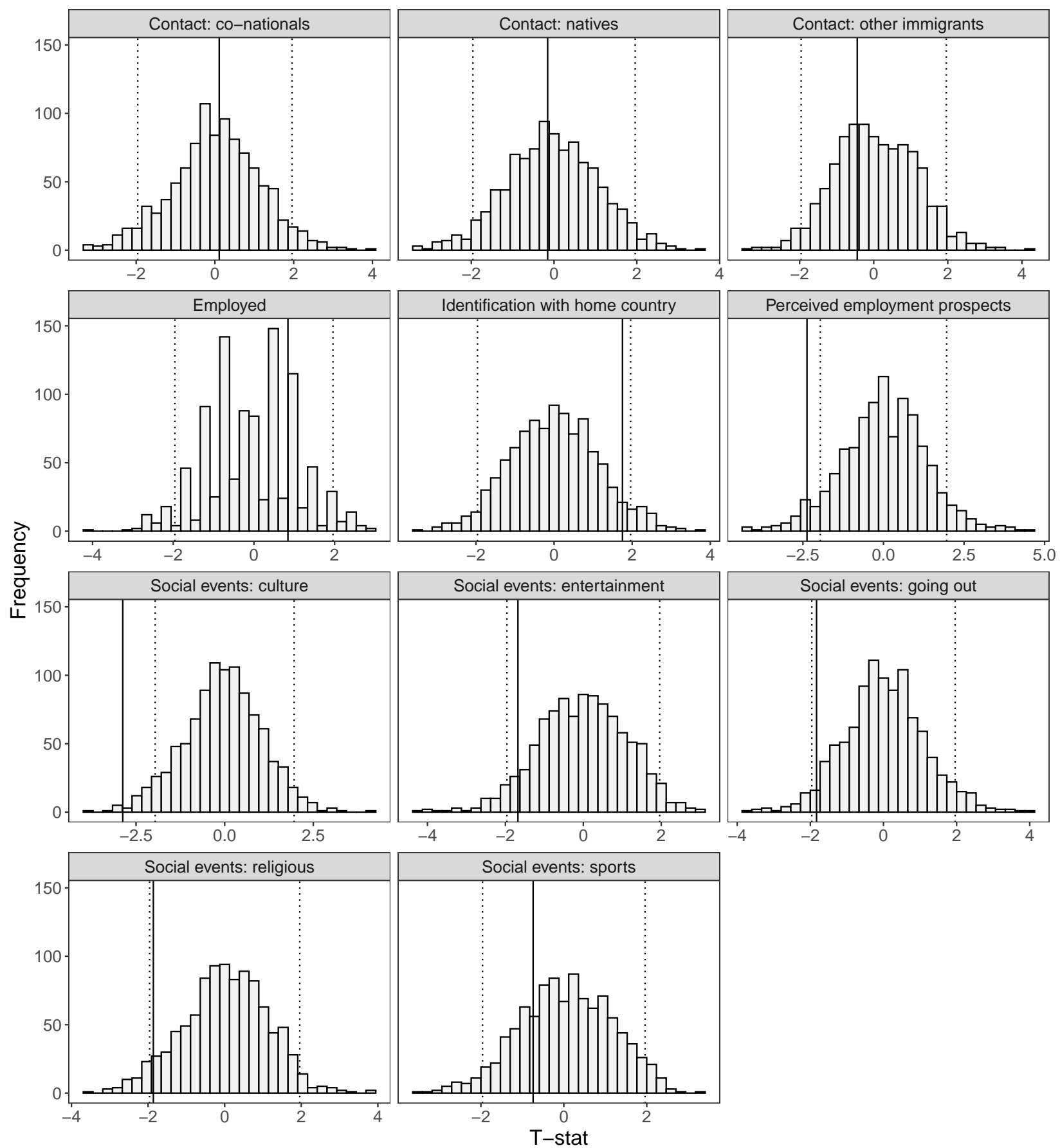

Note: The histograms show the distribution of the t-statistic for the treatment effect estimate over 1,000 random permutations of the treatment assignment vector. For each outcome variable, we conduct the same regression analysis with block-fixed-effects as for our main results presented in figure 1. The outcome variables are measured in 2017. 
Figure A.15: Randomization inference, 2018

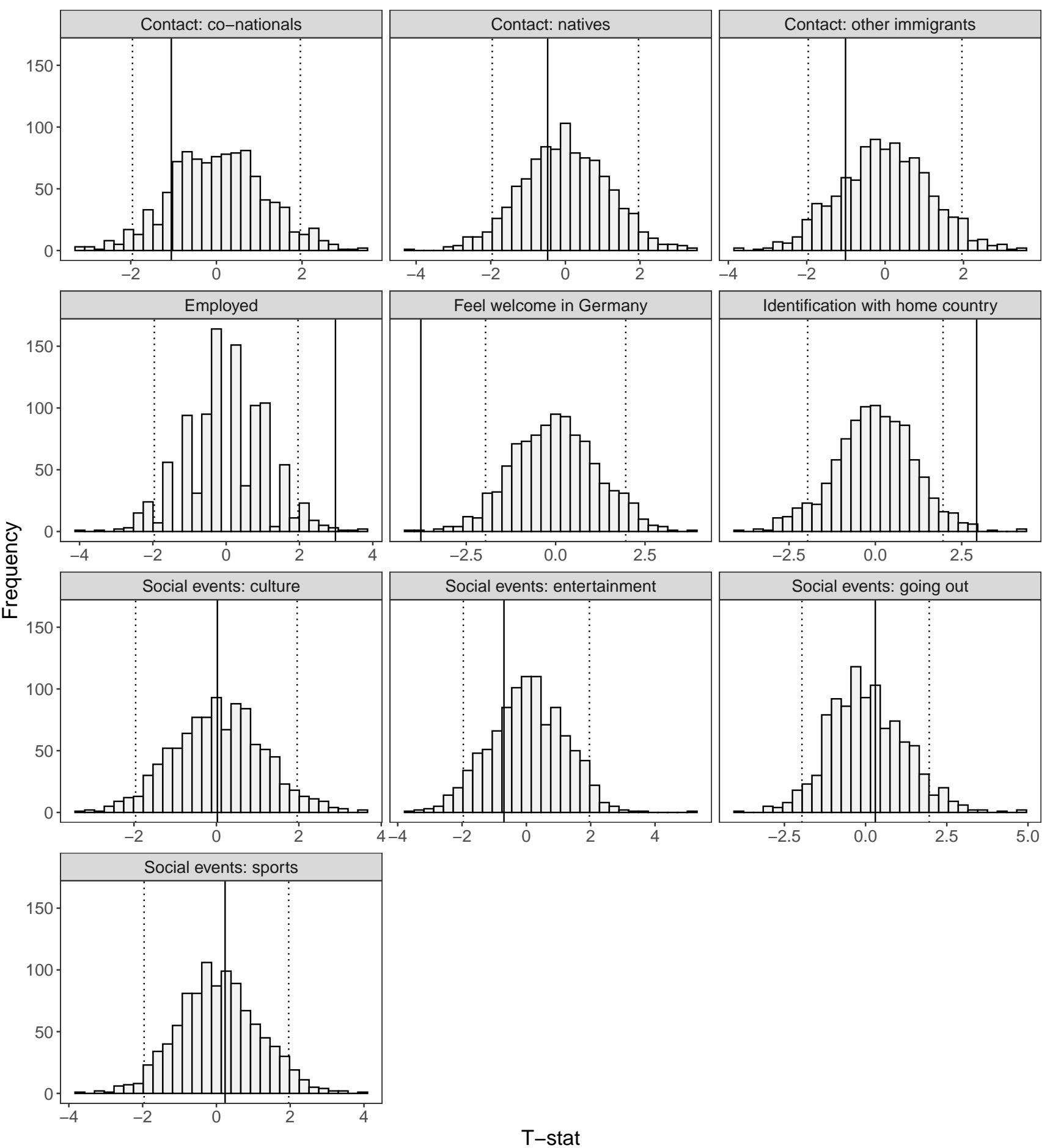

Note: The histograms show the distribution of the t-statistic for the treatment effect estimate over 1,000 random permutations of the treatment assignment vector. For each outcome variable, we conduct the same regression analysis with block-fixed-effects as for our main results presented in figure 1. The outcome variables are measured in 2018. 


\section{A.13.7 Pooling 2017 and 2018 survey waves}

Figure A.16: Effect of movement restrictions, pooling 2017 and 2018 SOEP waves

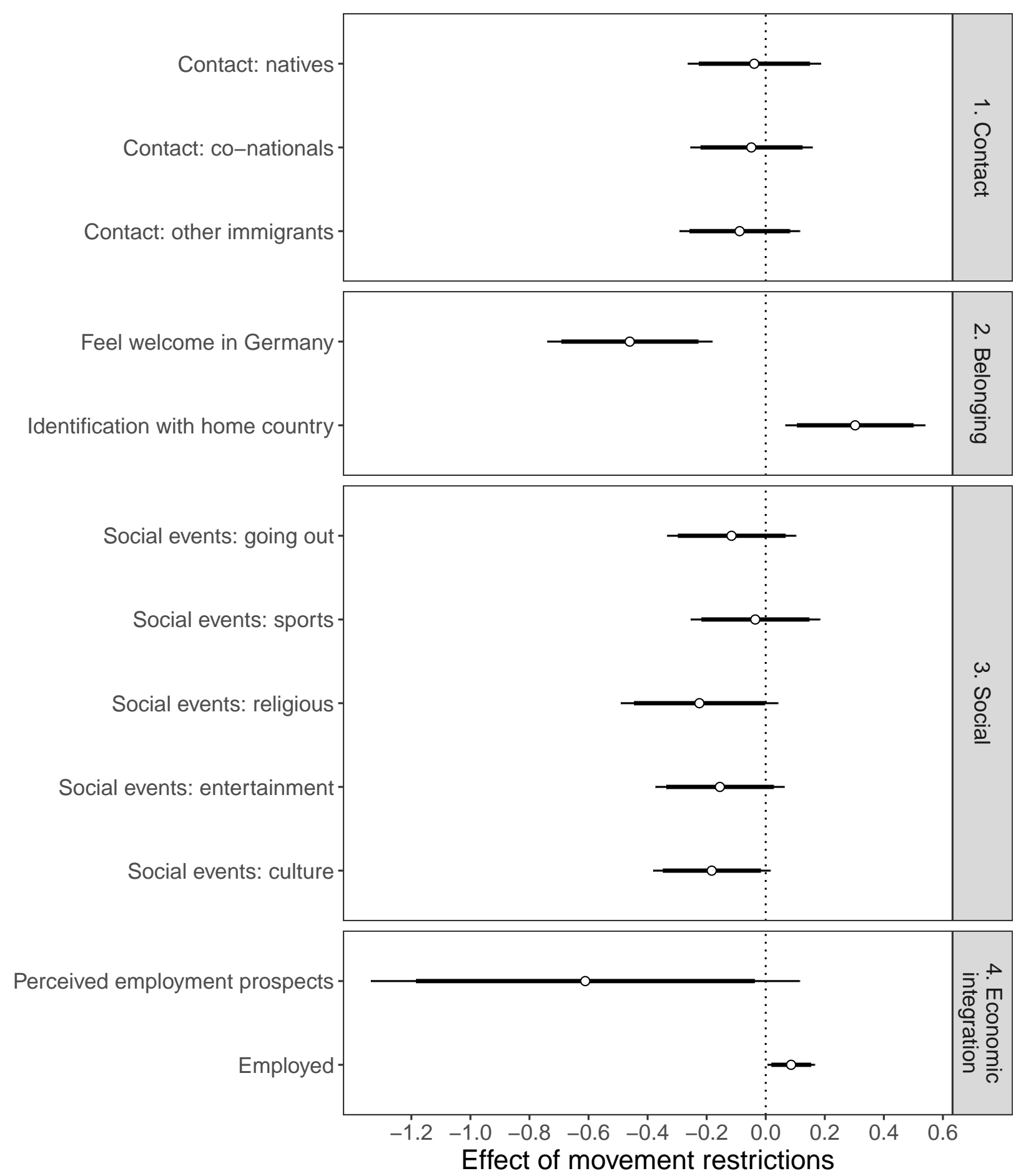

Note: The figure shows estimated effects of being subject to movement restrictions on the outcomes listed on the left-hand side. The horizontal bars represent $90 \%$ (thick lines) / 95\% (thin lines) confidence intervals. In contrast to the main model, we pool the 2017 and 2018 survey waves. All models include Block*Year fixed effects. We cluster standard errors by respondent. 


\section{A.13.8 Regression discontinuity estimates}

In addition to the main results presented in figure 1, we now discuss an alternative regression discontinuity specification, where we use months relative to January 2016 as the running variable. For the set of outcomes presented in the paper, we estimate a series of models of the following form:

$$
y_{i, j}=\alpha+\tau D_{i}+\gamma X_{i}+\delta D_{i} \times X_{i}+\sum_{j=2}^{M} \beta_{j} B_{i, j}+\epsilon_{i}
$$

The specification includes an indicator for the treatment assignment $D_{i}$, as well as the running variable $X_{i}$. The running variable $X_{i}$ is defined as months relative to January 2016, such that December 2015 corresponds to $X_{i}=-1$, January 2016 corresponds to $X_{i}=1$, February 2016 corresponds to $X_{i}=2$, and so on. Since we include both $X_{i}$ and the interaction between $D_{i}$ and $X_{i}$, we allow the relationship between $X_{i}$ and $y_{i, j}$ to vary depending on whether respondents are subject to movement restrictions or not. The sample we use is all respondents within six months of the January 2016 cutoff. To improve precision, we also control for covariate blocks $B_{i, j}$ (see section 4 on more details on covariate block construction). Figures A.2, A.3, A.4 and A.5 are visual representations of this specification for different sets of outcomes - we are interested in the jump in the regression function right around the cutoff, which corresponds to the parameter $\tau$.

We present the results from the regression discontinuity specification in figure A.17. While there are small differences in point estimates and confidence intervals compared to the main results in figure 1, our main conclusions remain unchanged. 
Figure A.17: Effect of movement restrictions, regression discontinuity design

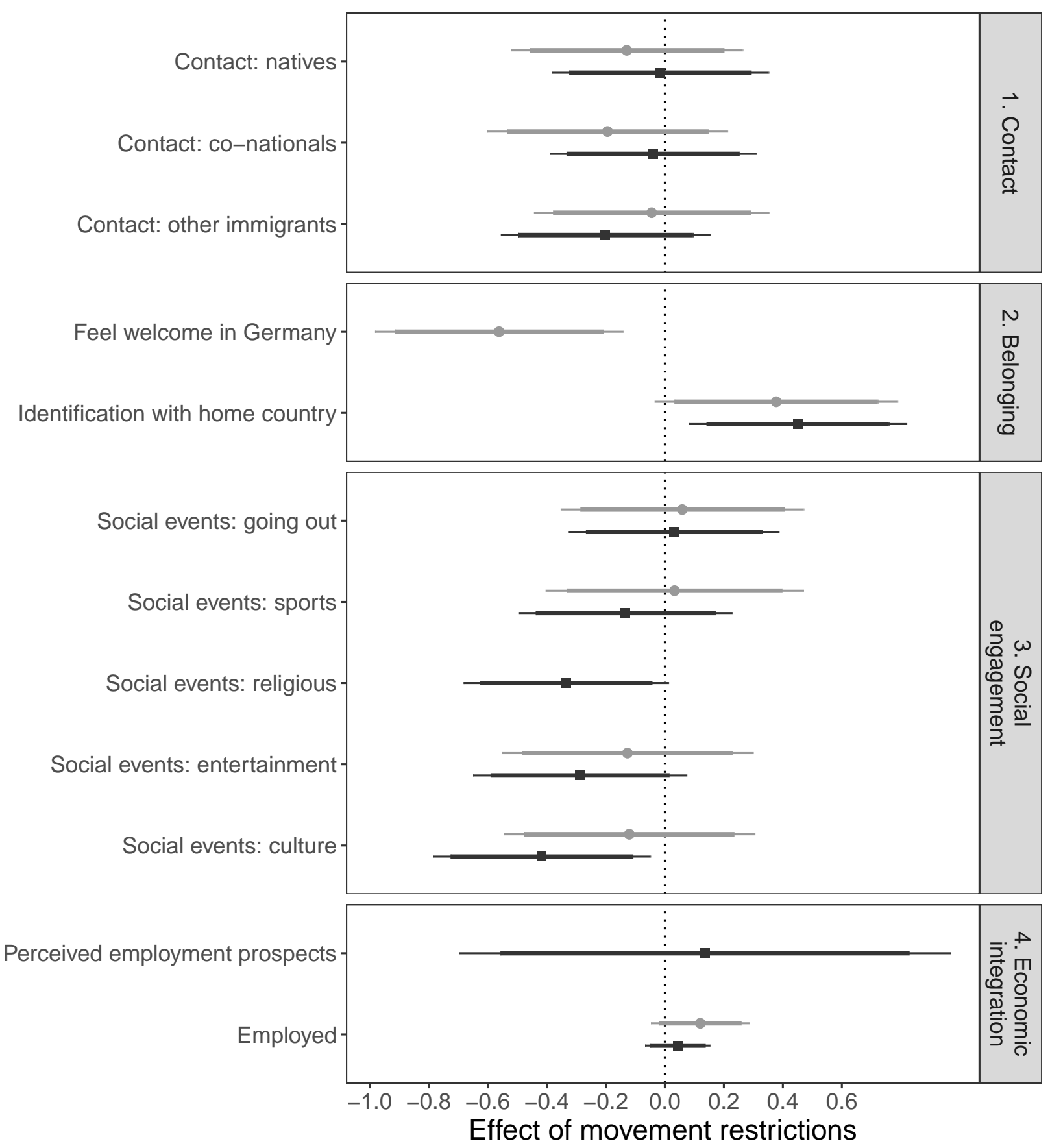

$\rightarrow$ Surveyed in $2017 \multimap$ Surveyed in 2018

Note: The figure shows estimated effects of being subject to movement restrictions on the outcomes listed on the left-hand side. We estimate the models using the regression discontinuity design discussed in section A.13.8. The horizontal bars represent 90\% (thick lines) / 95\% (thin lines) confidence intervals. All variables are standardized except employment status. 


\section{A.13.9 Effect on outcomes measured prior to treatment (placebo)}

Figure A.18: Effect of movement restrictions on 2016 outcomes

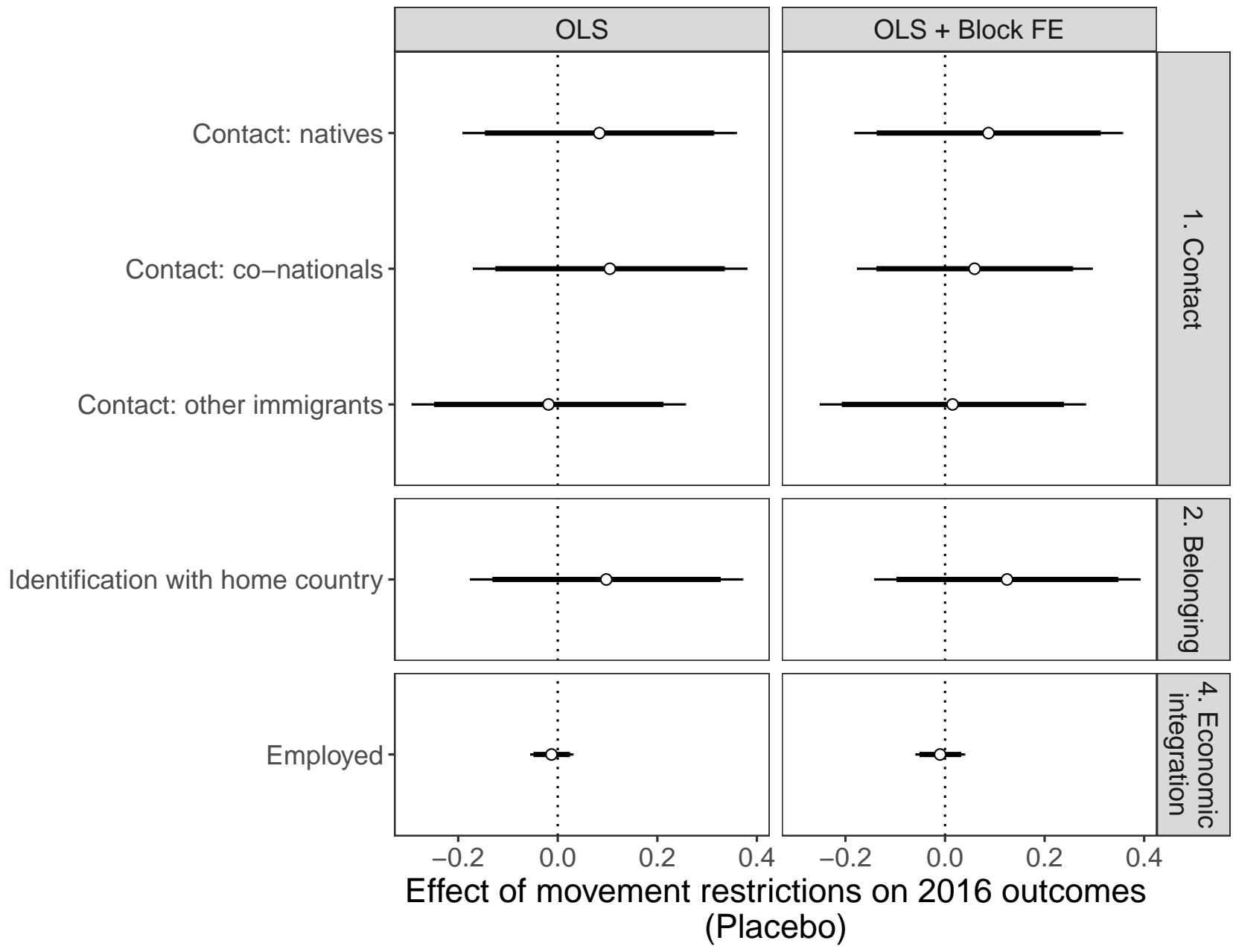

Note: The figure shows estimated effects of being subject to movement restrictions on the outcomes listed on the left-hand side. The horizontal bars represent 90\% (thick lines) / 95\% (thin lines) confidence intervals. The lefthand side panel is a simple OLS specification, the right-hand panel includes block fixed effects. The outcomes were measured as part of the 2016 survey wave of the SOEP panel. A subset of the survey interviews was conducted after the law entered into force in August 2016. However, depending on the federal state, regulations to remain in a specific county were only passed a couple of weeks or months after August 2016. We hence consider this analysis as a test for pre-treatment differences around the assignment cutoff. 


\section{A.13.10 Omitting non-Syrians}

Figure A.19: Effect of movement restrictions, omitting non-Syrians

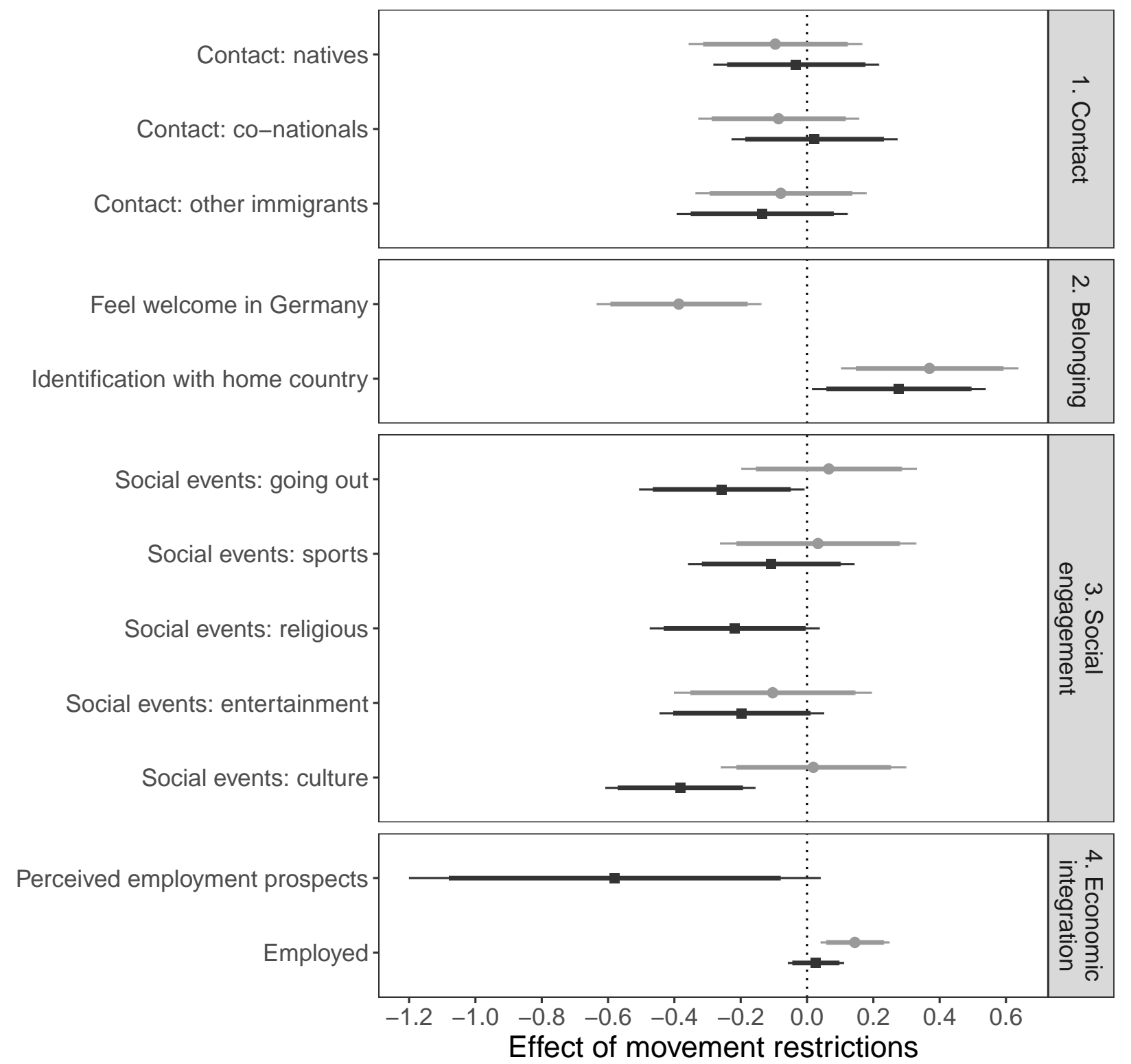

$\rightarrow$ Surveyed in $2017 \multimap$ Surveyed in 2018

Note: The figure shows estimated effects movement restrictions on the outcomes listed on the left-hand side. The sample omits non-Syrians. The horizontal bars represent 90\% (thick lines) / 95\% (thin lines) confidence intervals. All variables are standardized except employment status, which is binary. The sample is based on a two-month bandwidth around the Jan 1, 2016 cutoff. 


\section{A.13.11 Balance on pre-migration characteristics}

In this supplementary analysis, we establish balance on pre-migration covariates between affected and unaffected refugees. Specifically, we examine balance on the following items:

- At your arrival, did you have any support from relatives who already lived in Germany? $(0 / 1)$

- When you moved to Germany, did you have the help of any friends who already lived in Germany? (0/1)

- How well did you know German (speaking, writing, reading) before moving to Germany? (coded as 1 for respondents who indicate any language skills prior to migration, 0 otherwise)

- How satisfied were you with your life in general prior to the conflict in your home country? Ranges from 0 (completely unsatisfied) to 10 (completely satisfied)

- To code traumatic experiences during the migration journey, we use the following survey item: "During the journey or escape, did you experience one or more of the following? (financial fraud or financial exploitation, sexual harassment, physical attacks, shipwreck, robbery, blackmail, imprisonment)" - we code this item as 1 for respondents who indicate to not have experienced any of these events. 
Figure A.20: Effect of movement restrictions on characteristics observed prior to immigration

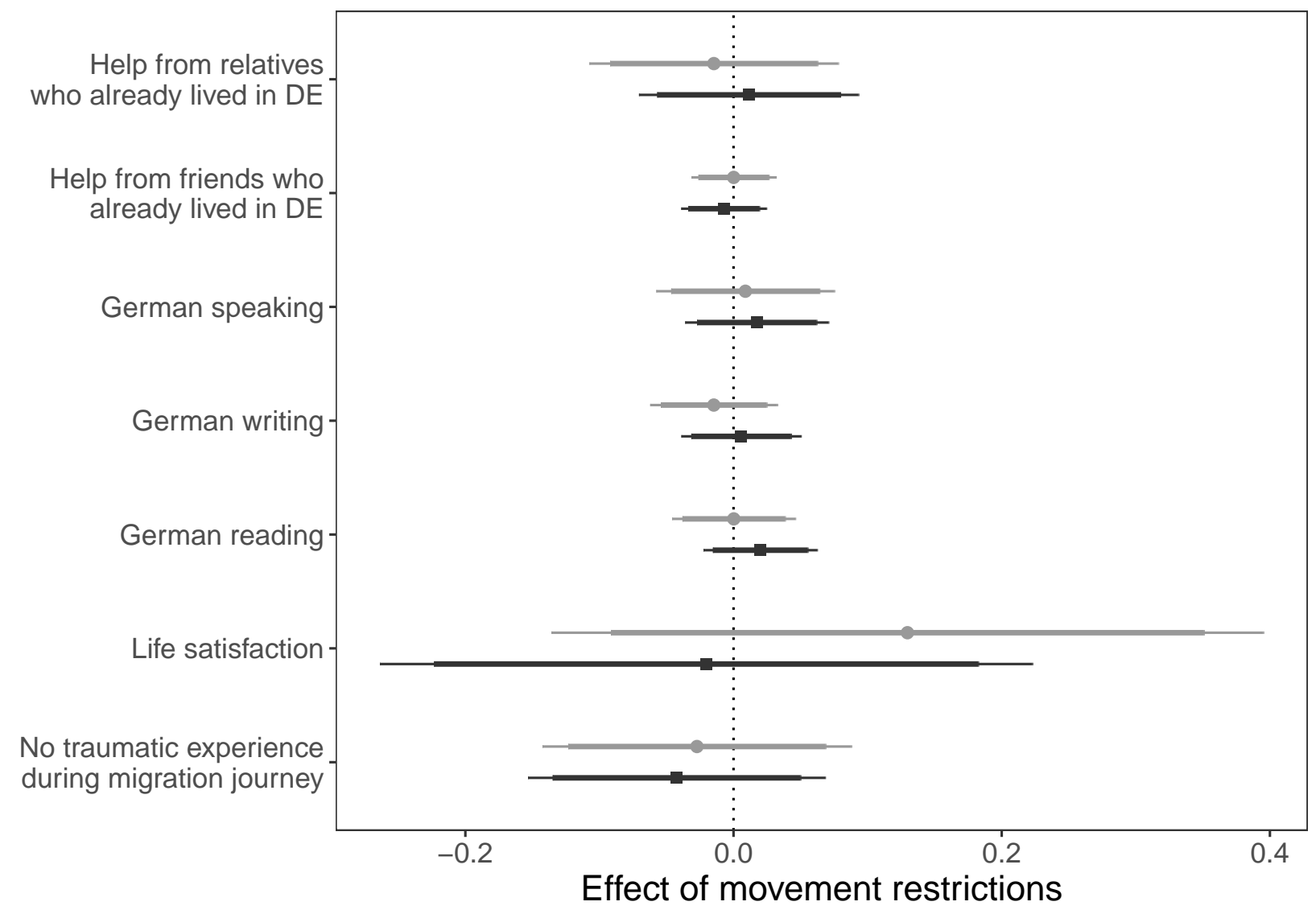

$\rightarrow$ Surveyed in $2017 \rightarrow$ Surveyed in 2018

Note: The figure shows estimated effects of being subject to movement restrictions on the outcomes listed on the left-hand side. All outcomes shown refer to the period before refugees entered Germany. The horizontal bars represent 90\% (thick lines) / 95\% (thin lines) confidence intervals. All models include block fixed effects. All variables except life satisfaction are binary. Life satisfaction is measured in standard deviations. 


\section{A.13.12 Effect of application decision speed on outcomes}

Figure A.21: Effect of application decision speed

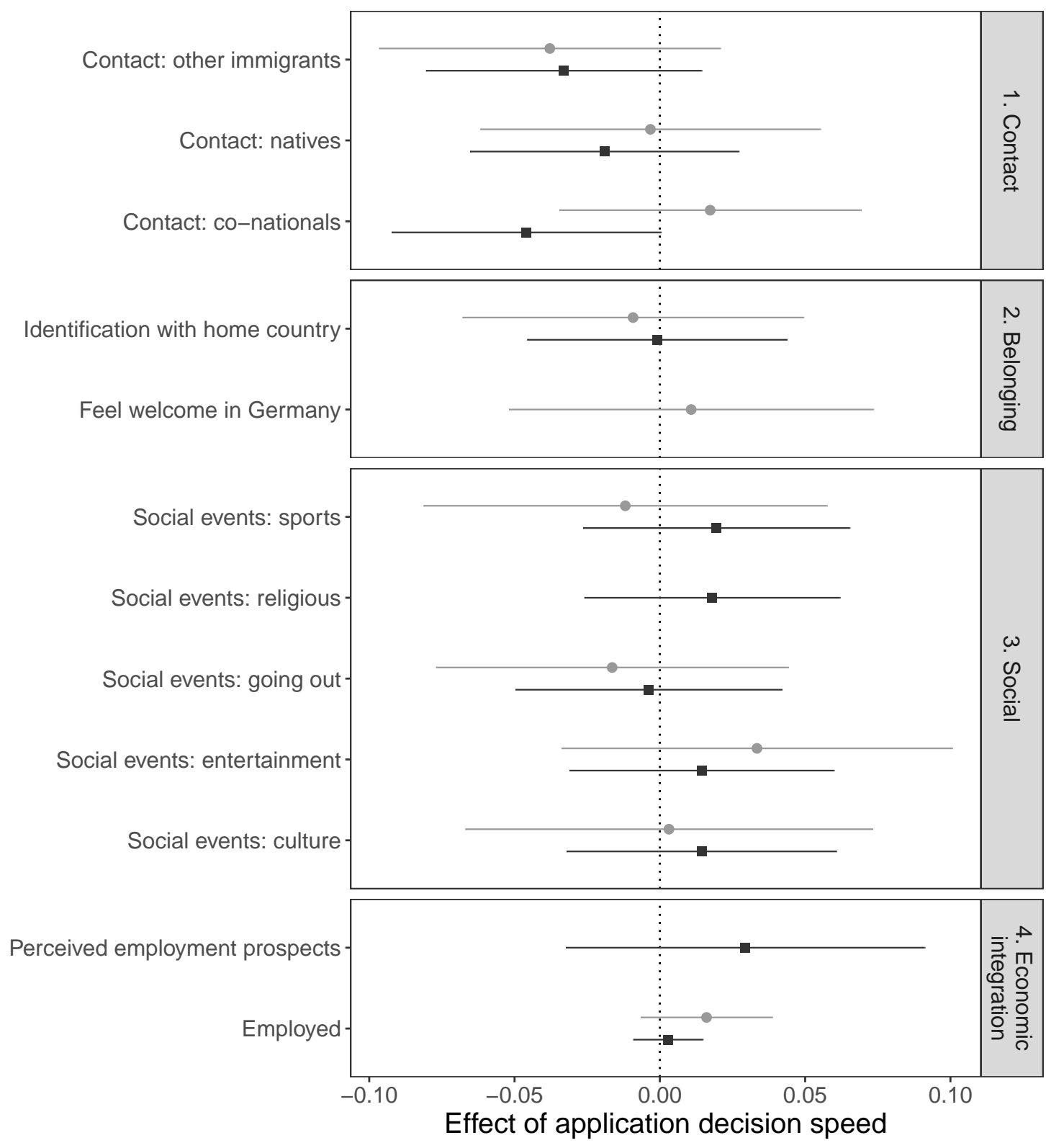

$\rightarrow$ Surveyed in $2017 \multimap$ Surveyed in 2018

Note: The figure shows the results from OLS regressions where we regress the same outcome variables as in our main analysis on the time in months between the arrival date of a refugee and the asylum application decision date. Similar to our main analysis, the models include block fixed effects. The blocks are defined by the same covariates as for our main analysis (gender, age, education, nationality, and arrival quarter-year) plus the asylum application decision time in intervals of 4 months. We hence compare refugees with similar background characteristics whose asylum applications were processed within a time window of 4 months. This corresponds to the 2 -months bandwidth around the treatment assignment cutoff used for our main analysis. We exclude outcomes for which fewer than 200 observations are available within a given survey year. 


\section{A.13.13 Effect of pre-migration covariates on application decision speed}

Figure A.22: Effect of pre-migration covariates on application decision speed

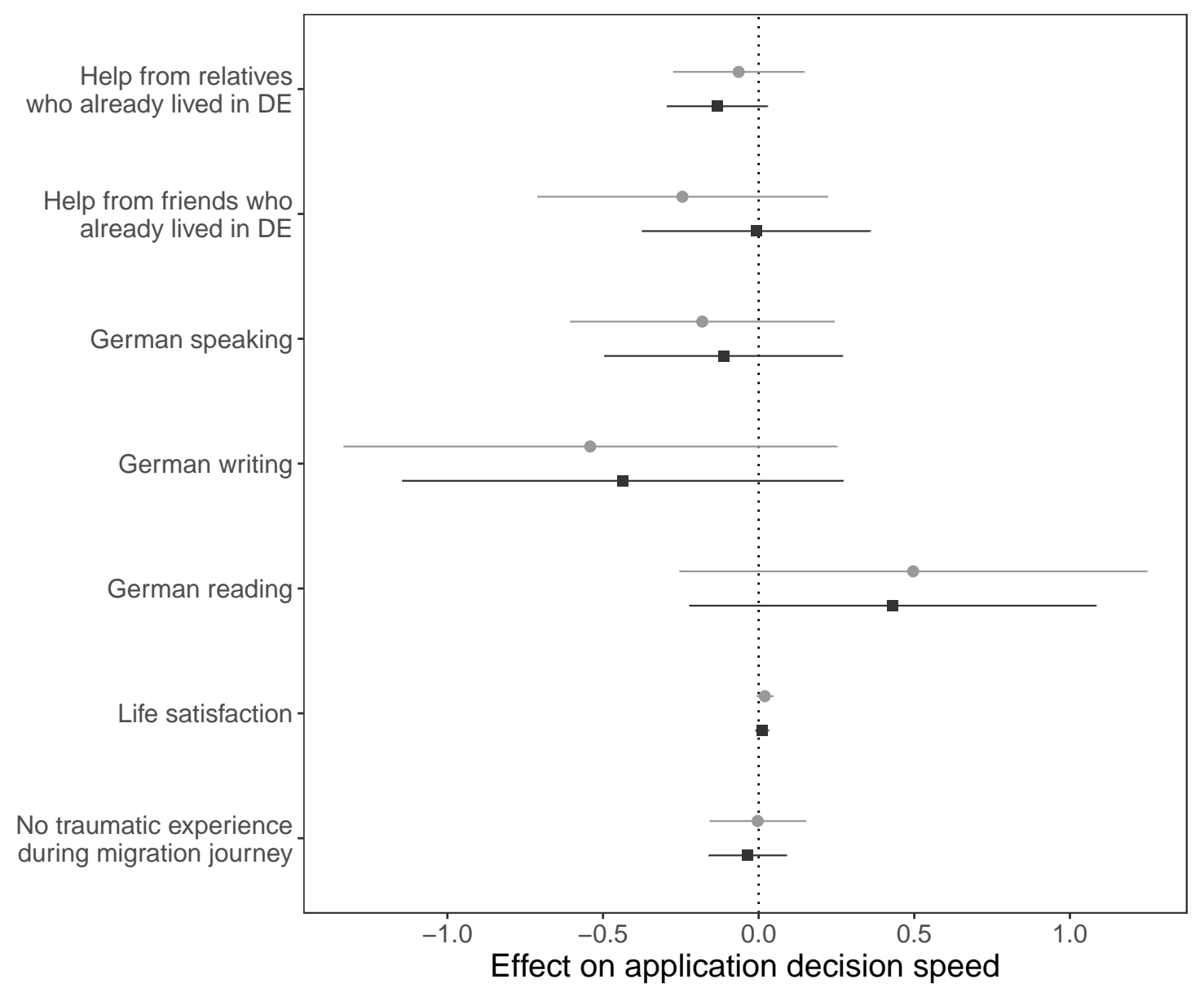

$\rightarrow$ Surveyed in $2017 \rightarrow-$ Surveyed in 2018

Note: The figure shows the results from OLS regressions where we regress the time in months between the arrival date of a refugee and the asylum application decision date on several pre-migration covariates. We estimate separate models for 2017 and 2018. Similar to our main analysis, the models include block fixed effects. The blocks are defined by the same covariates as for our main analysis (gender, age, education, nationality, and arrival quarteryear) plus the asylum application decision time in intervals of 4 months. We hence compare refugees with similar background characteristics whose asylum applications were processed within a time window of 4 months. This corresponds to the 2-months bandwidth around the treatment assignment cutoff used for our main analysis. The covariates are described in more detail in section A.13.11. 


\section{A.14 Heterogeneity}

\section{A.14.1 Differential effects in urban and rural areas}

Figure A.23: Differential effects in urban and rural areas

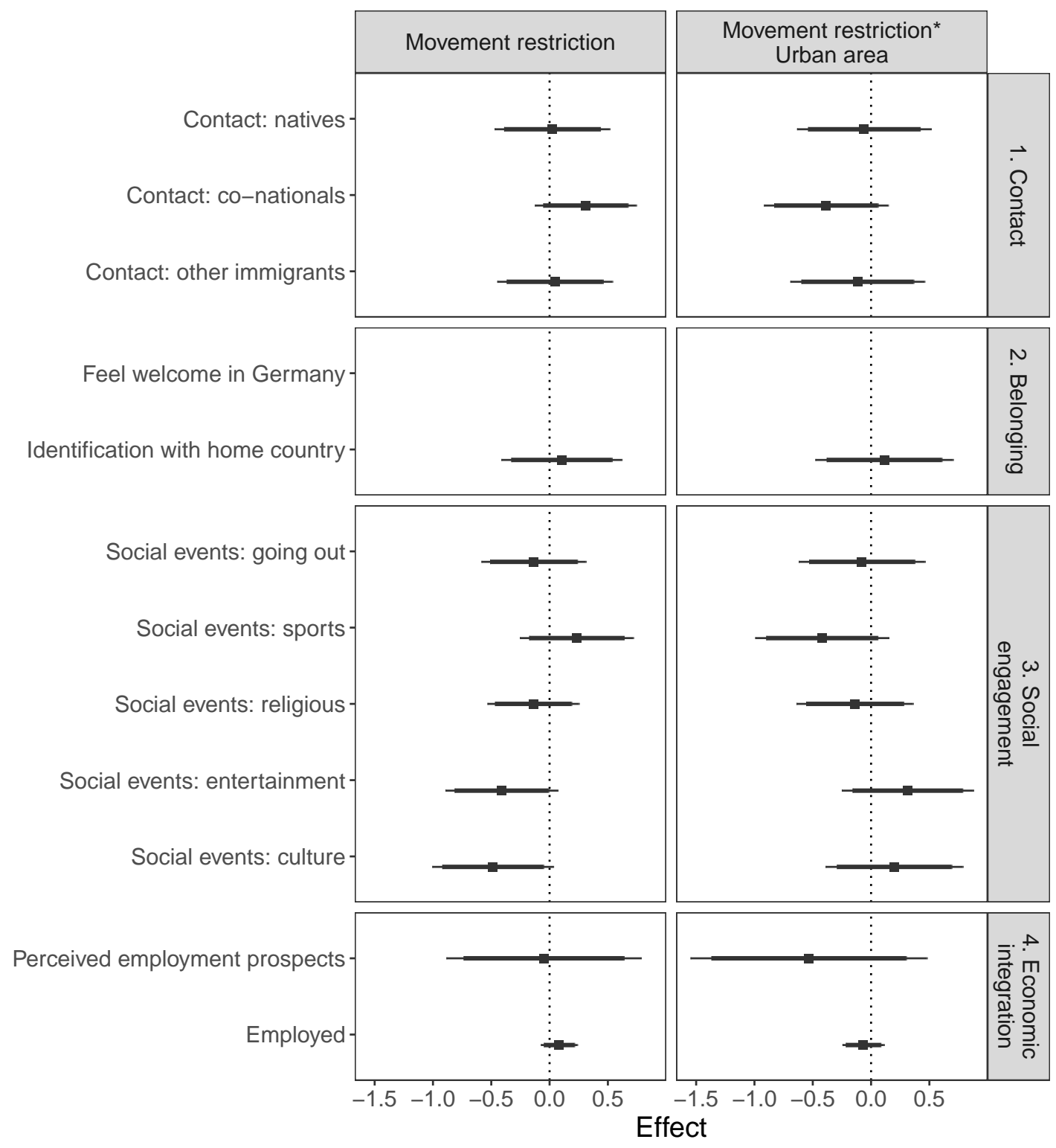

Surveyed in $2017 \rightarrow$ Surveyed in 2018

Note: We present results from interacting movement restriction with a binary rural/urban indicator, as defined by the Federal Institute for Research on Building, Urban Affairs and Spatial Development (BBSR). The left-hand side panel represents the effect of movement restrictions for refugees in rural areas. The right-hand side panel is the restriction*urban interaction. The rural/urban indicator is not available in the 2018 survey wave. The horizontal bars represent $90 \%$ (thick lines) / 95\% (thin lines) confidence intervals. All variables are standardized except employment status, which is binary. The sample is based on a two-month bandwidth around the Jan 1, 2016 cutoff. 


\section{A.14.2 Differential effects in city states}

Figure A.24: Interacting movement restrictions with a city state indicator

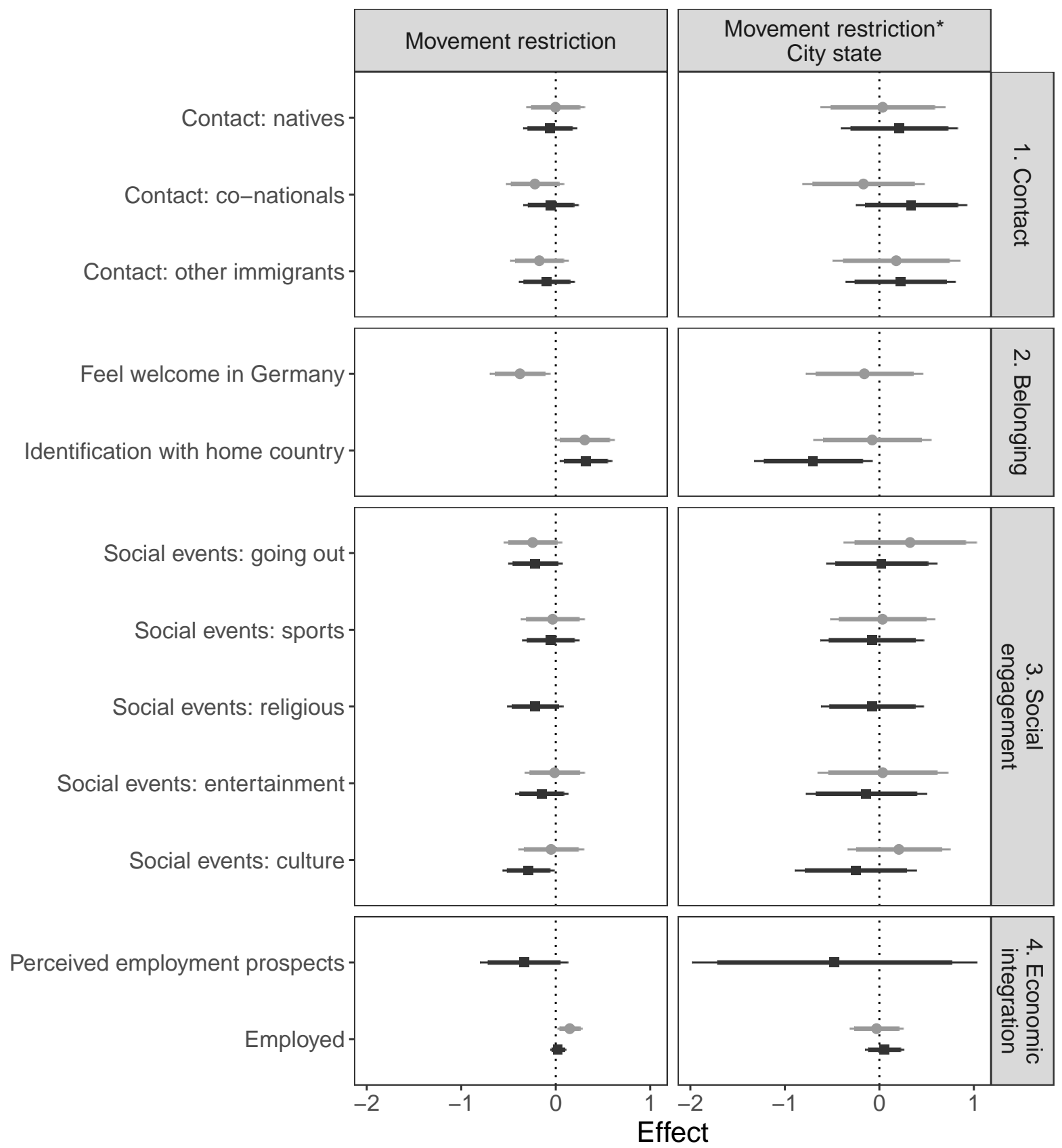

$\rightarrow$ Surveyed in $2017 \rightarrow$ Surveyed in 2018

Note: We present results from interacting movement restriction with a binary indicator for city-states (Berlin, Hamburg, and Bremen). The left-hand side panel represents the effect of movement restrictions for refugees in non-city states. The right-hand side panel is the restriction*city-state interaction. The horizontal bars represent 90\% (thick lines) / 95\% (thin lines) confidence intervals. All variables are standardized except employment status, which is binary. The sample is based on a two-month bandwidth around the Jan 1, 2016 cutoff. 


\section{A.14.3 Differential effects in states with and without county movement restrictions}

In this section, we examine heterogeneity across states. Specifically, we estimate interaction models between the individual-level movement restriction indicator and a binary measure that indicates whether the state a refugee resides in allows movement between counties.

As of 2018, the following states had enacted within-state movement restrictions that go beyond federal law: Bavaria, Baden-Württemberg, Hesse, North Rhine-Westphalia, Saarland, Saxony, Saxony-Anhalt (Deutscher Bundestag 2018). These states account for about $73 \%$ of Germany's population and hence receive roughly three-quarters of all incoming refugees. Berlin, Bremen, and Hamburg are city-states, hence refugees are not allowed to move outside of city borders by construction.

We present the results from this analysis in figure A.14.3. We do not find statistically significant differences between states that limit within-state movement and those that do not. However, we caution against over-interpreting these results. The state location is observed after the enactment of the movement restriction policy (post-treatment), and the sample size is small for states that did not enact within-state movement restrictions. 
Figure A.25: Interacting movement restrictions with and indicator for the absence of county movement restrictions

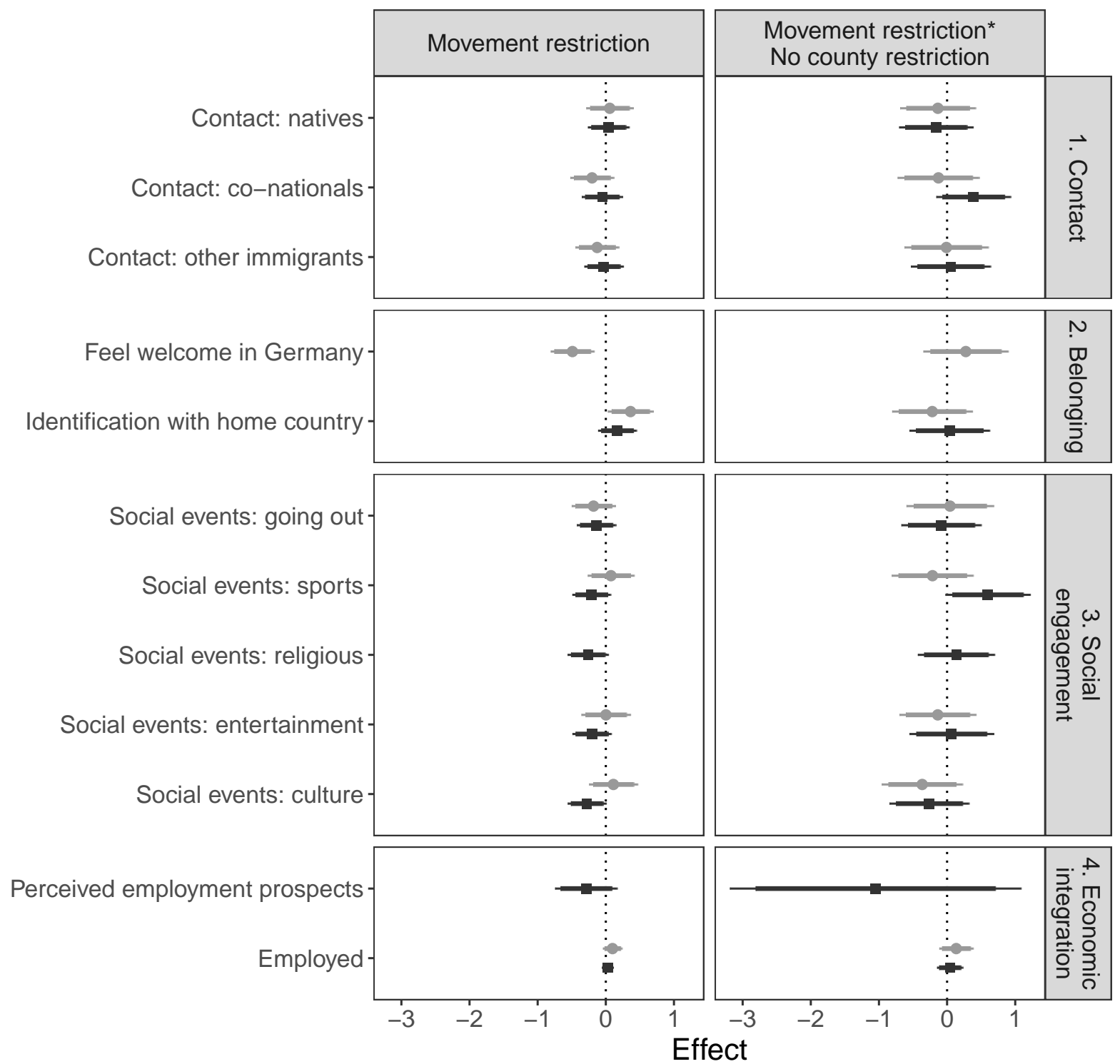

$\because$ Surveyed in $2017 \approx$ Surveyed in 2018

Note: We present results from interacting movement restriction with a binary indicator for states that allow movement between counties within the state. The left-hand side panel represents the effect of movement restrictions for refugees in states that ban movement between counties. The right-hand side panel is the interaction between movement restrictions at the individual level and the absence of between-county movement bans on the state level. The horizontal bars represent 90\% (thick lines) / 95\% (thin lines) confidence intervals. All variables are standardized except employment status, which is binary. The sample is based on a two-month bandwidth around the Jan 1, 2016 cutoff. 


\section{A.14.4 Differential effects conditional on education}

Prior research has shown that second-generation immigrants and immigrants who are well integrated are more likely to report perceived discrimination in surveys. Gillum (2018) documents that second-generation Muslim Americans hold higher expectations for nondiscrimination compared to Muslims who were not born in the United States. Steinmann (2019) documents a similar dynamic in the German context. Drawing on a large-scale survey of immigrants in Germany, Steinmann finds a positive correlation between educational attainment and perceived discrimination. van Doorn, Scheepers and Dagevos (2013) and de Vroome, Martinovic and Verkuyten (2014) report similar findings in the Dutch context.

Gillum (2018) highlights the importance of the reference point that immigrants hold when evaluating perceived discrimination. In light of these findings, it is possible that refugees who were born in comparatively free societies hold higher expectations and are more likely to perceive

discrimination. For example, the policy might have a stronger effect on Syrians compared to Afghan refugees. Unfortunately, we are unable to explore this theoretical implication empirically, as our matched sample is almost entirely composed of Syrian refugees. We also note that in the asylum context, most countries of origin are autocracies and/or civil war zones in which human rights violations commonly occur.

Another theoretical implication is that non-refugee immigrants from relatively liberal countries (e.g. Bulgaria or Poland), or second-generation children of refugees would perceive a movement restriction as even more discriminatory than refugees. While plausible, we are unable to test this empirical implication because refugees who were not born in Germany are the only immigrant group that is subject to domestic movement restrictions. The movement restriction subjects refugees to clear, legal discrimination compared to other immigrants (and natives). It is however possible that refugees feel less discriminated against in other domains (e.g. in day-to-day interactions with German natives) compared to other immigrant groups.

Prior research van Doorn, Scheepers and Dagevos 2013; de Vroome, Martinovic and Verkuyten 2014: Steinmann 2019) suggests a positive relationship between integration and perceived discrim- 
ination. In our context, an empirical implication of this argument is that highly educated refugees might be most likely to perceive the movement restriction as a discriminatory signal. Indeed, this is what the qualitative interviews of affected refugees suggest (see section A.16).

We also explore this theoretical implication quantitatively. Specifically, we test whether highly educated refugees are more strongly affected by the policy. We define a binary indicator for high education based on a median split of the ISCED 2011 education levels we observe in the SOEP survey. We then estimate models where we interact the treatment variable with the high education dummy. For this analysis, we combine the 2017 and 2018 survey waves to maximize statistical power. We also omit the block FE, because the interaction effect would not be identified otherwise. Within covariate blocks, there is no residual variation in refugee education.

We find evidence that the negative effects of the movement restriction policy on social engagement are more pronounced among highly educated refugees. We also find suggestive evidence that, among highly educated refugees, the movement restriction policy reduces contact with natives and other immigrants. The results are presented in figure A.26.

Finally, we would like to note that in contrast to prior research on perceived discrimination, our study examines an immigrant group that is subject to explicit legal discrimination. While related, we argue that the extent and visibility of discrimination is stronger in our setting compared to other contexts. Muslim Americans for instance are generally US citizens who (at least formally) hold the same rights as all other US citizens. With few exceptions, European immigrants and second-generation Turkish immigrants in Germany are legal equals to German natives. While nonrefugee immigrants are subject to various forms of subtle, implicit discrimination (White, Nathan and Faller 2015; Hemker and Rink 2017; Alizade and Ellger 2020), formal legal discrimination against immigrants is a rare phenomenon. 
Figure A.26: Heterogeneity by education

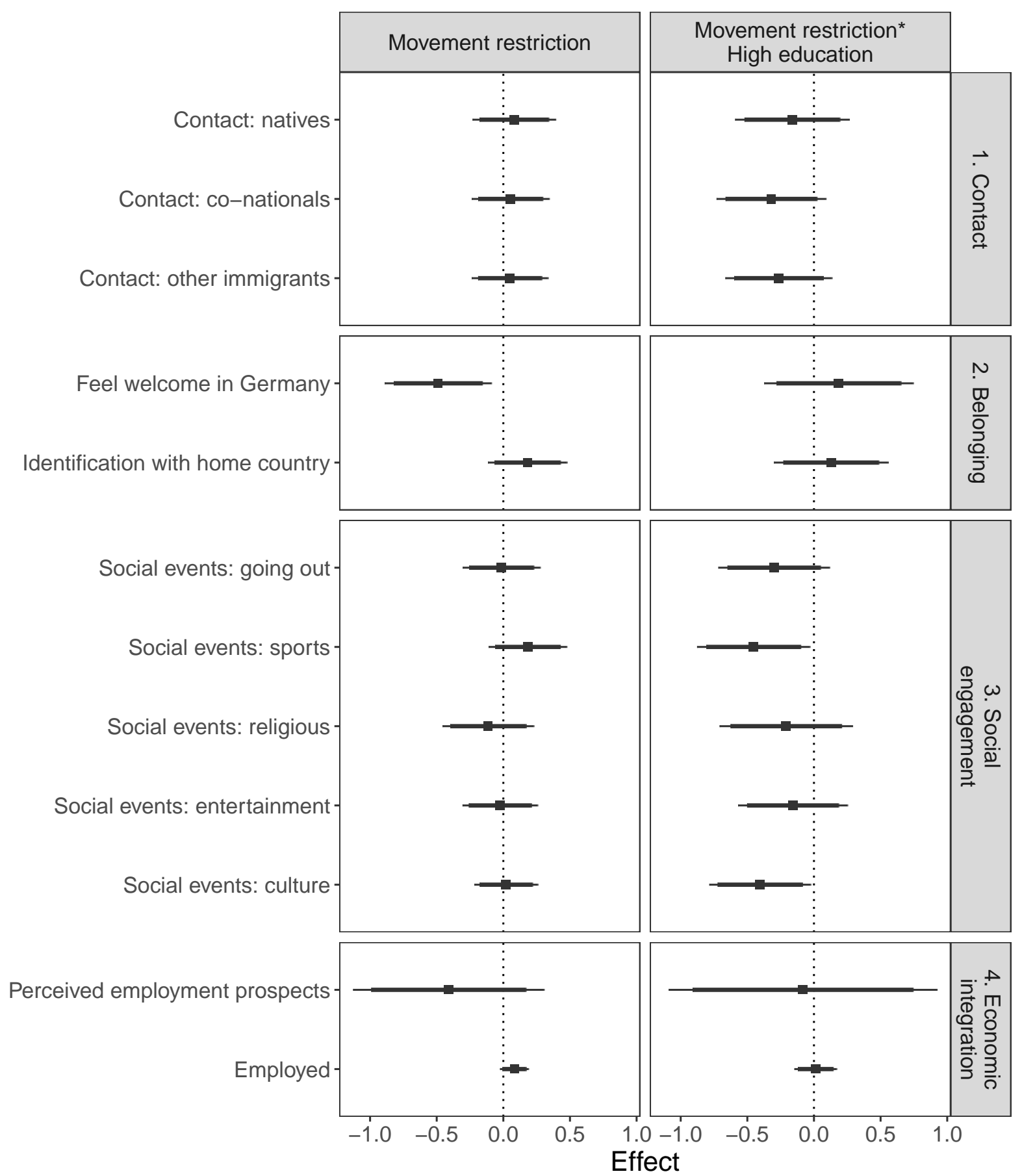

Note: We present results from interacting movement restriction with a binary indicator for high education. The high education indicator is based on a median split of the ISCED 2011 education levels we observe in the SOEP survey. The left-hand side panel represents the effect of movement restrictions for refugees with below-median education. The right-hand side panel is the restriction*high education interaction. The horizontal bars represent 90\% (thick lines) / 95\% (thin lines) confidence intervals. All variables are standardized except employment status, which is binary. The sample is based on a two-month bandwidth around the Jan 1, 2016 cutoff. For this analysis, we pool the 2017 and 2018 waves of the SOEP survey. 


\section{A.15 Additional outcomes}

\section{A.15.1 Effect on German language acquisition, integration course participation and interest in contact with Germans}

In this section, we examine the effect of the movement restriction on a number of additional SOEP items:

- German-speaking/writing/reading ability, rated on a scale from 1 (not at all) to 5 (very good)

- Have you attended an integration course organized by the German Federal Ministry for Migration and Refugees (BAMF)? (0/1)

- Regular, e.g. weekly, contact between refugees and locals is a good way for refugees to improve their German. Scale from 1 (completely Disagree) to 7 (agree completely).

- Regular, e.g. weekly, contact between refugees and locals is a good way to quickly build up a circle of friends and acquaintances in Germany. Scale from 1 (completely Disagree) to 7 (agree completely).

- Regular, e.g. weekly, contact between refugees and locals is a good way for both groups to improve their understanding of each other's cultural customs and traditions. Scale from 1 (completely Disagree) to 7 (agree completely). 
Figure A.27: Effect of movement restrictions on German language acquisition, integration course participation and interest in contact with Germans

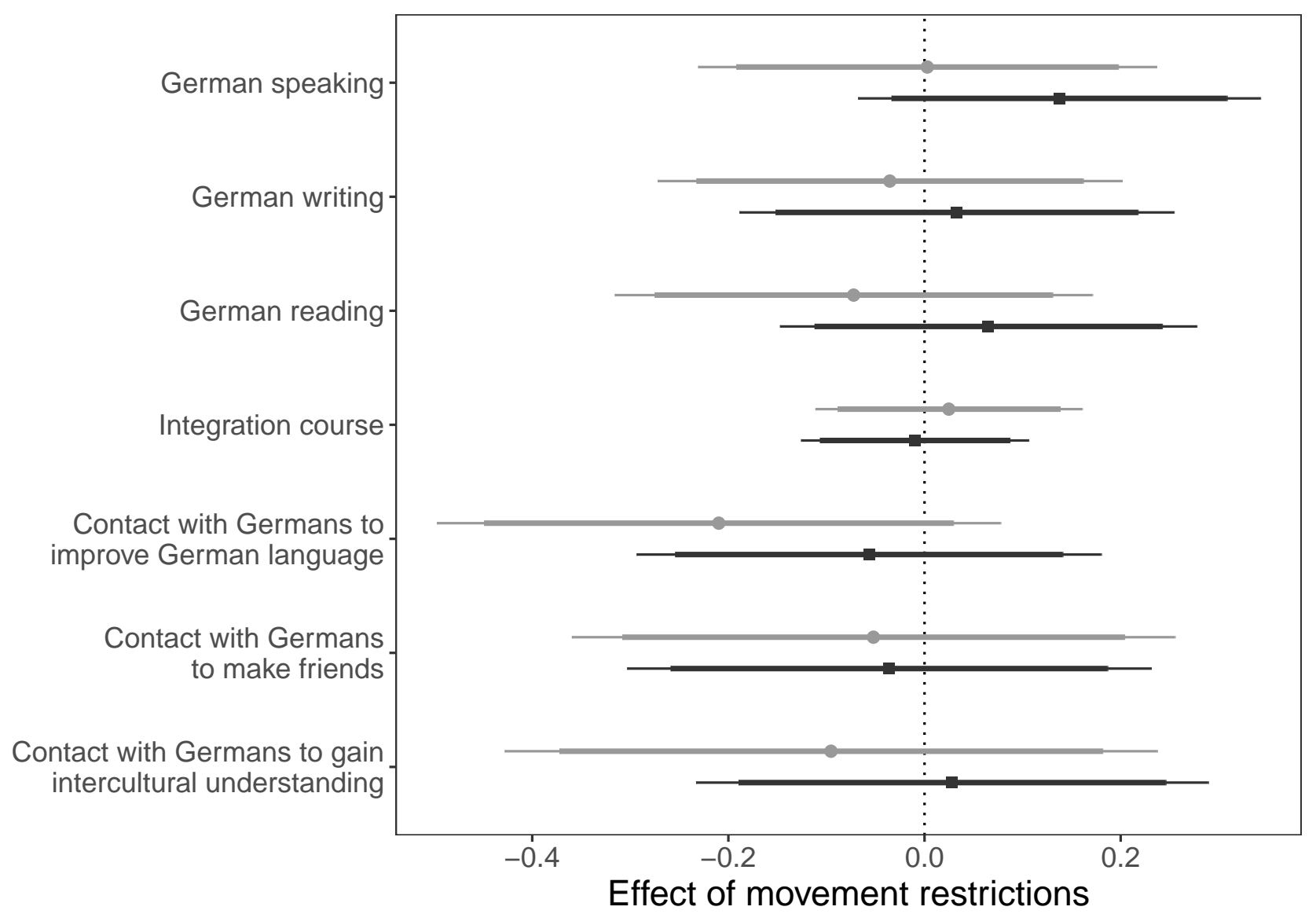

$\rightarrow$ Surveyed in $2017 \rightarrow$ Surveyed in 2018

Note: The figure shows estimated effects movement restrictions on the outcomes listed on the left-hand side. The horizontal bars represent 90\% (thick lines) / 95\% (thin lines) confidence intervals. All variables except integration course attendance are standardized. The sample is based on a two-month bandwidth around the Jan 1, 2016 cutoff. 


\section{A.15.2 Effects on life satisfaction}

In this section, we document that the movement restriction had a negative effect on the general life satisfaction of affected refugees. We employ a SOEP item that asks refugees to rate their general life satisfaction on a scale from 0 (low) to 10 (high) as follows:

"Finally, we would like to ask you about your satisfaction with your life in general.

How satisfied are you with your life, all things considered?"

We repeat exactly the same matching procedure and analysis as for our main results. Again, we use a two-month bandwidth around the treatment assignment cutoff and standardize the outcome prior to the analysis. We present the results in figure A.28. We find that the movement restriction decreased refugees' life satisfaction by about 0.2 standard deviations in the pooled sample. This

result is significant at the $90 \%$ level of confidence. We view this as additional quantitative evidence that ties in with the qualitative evidence presented in section A.16: the restrictive policy affected refugees' sense of well-being, belonging, and perceived prospects for successful integration in the host country. 
Figure A.28: Effect of movement restriction on life satisfaction

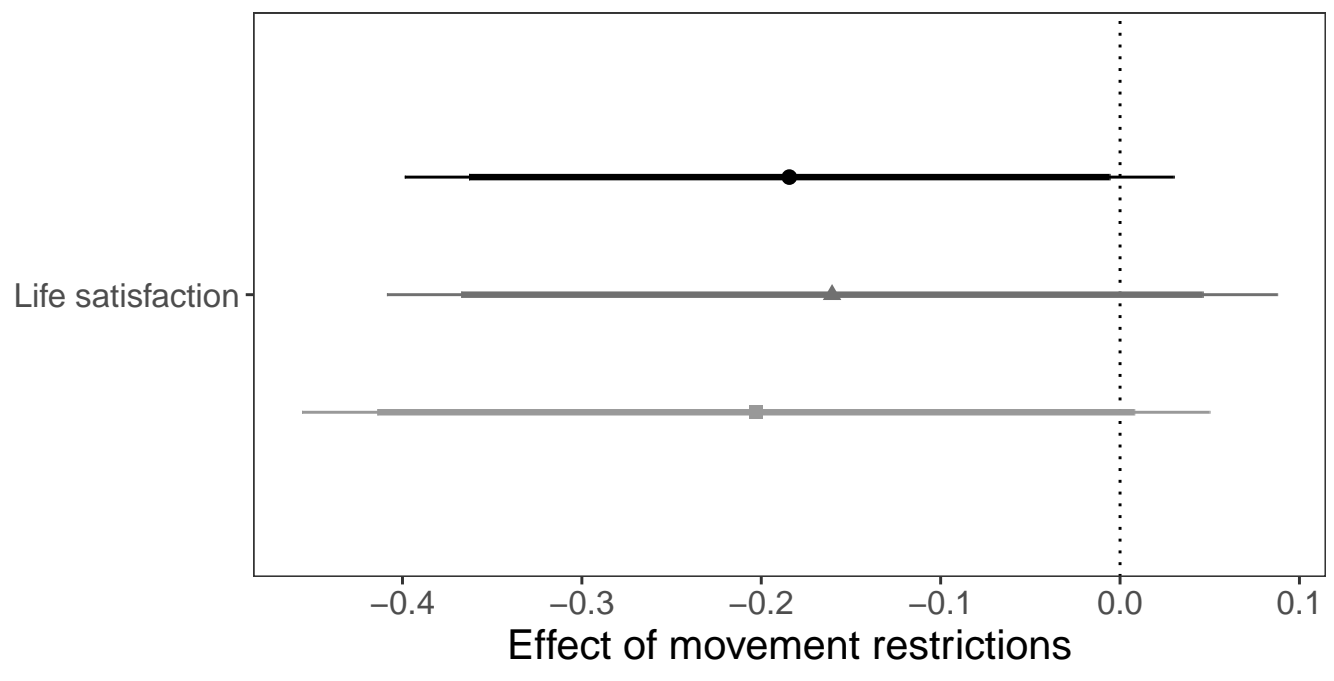

$\simeq$ Surveyed in $2017 \simeq$ Surveyed in $2018 \rightarrow$ Pooled

Note: The figure shows the results from OLS regressions. The outcome is general life satisfaction on a scale from 0 (low) to 10 (high). The treatment is the movement restriction policy. The horizontal bars represent $90 \%$ (thick lines) / 95\% (thin lines) confidence intervals. The sample is based on a two-month bandwidth around the Jan 1, 2016 cutoff. The outcome variable was standardized prior to the analysis. 


\section{A.16 Qualitative evidence for the mechanism}

In this section, we use qualitative evidence to shed more light on how movement restrictions were perceived among those affected, and how the policy may have led to the effects we describe in figure 1. A large-scale survey of how refugees perceived the movement restriction is, unfortunately, not available 9 Therefore, we rely on qualitative information and interviews with affected refugees to illustrate how the movement restriction was perceived. The qualitative evidence suggests that movement restriction was perceived as a highly restrictive policy, and consequently led to social withdrawal and reduced refugees' sense of belonging in Germany.

We first draw on qualitative interviews conducted by Koslowski (2017). Specifically, the author conducted qualitative interviews with four refugees in Bad Liebenzell, a small town in the Southwest of Germany. One of the interviewees, a 30-year-old refugee from Syria could not imagine a future for himself in the small town where he felt like he did not belong. Yet, due to the movement restriction, he was unable to move elsewhere and build a future for himself. He describes the situation as follows:

"Right now I'm literally stuck here, that's how I feel, stuck (...) in a place that I don't like (...) not because of the people but because I'm not used to this. It's really hard to be put somewhere you don't feel like you belong to" (Koslowski 2017, p. 40)

We see a similar sentiment expressed in the story of a 25-year-old refugee who was assigned to live in Bad Gottleuba-Berggießhübel, a small town of 5,700 people in the state of Saxony barthHasibullahBleibstHier2019. According to the interviewee, regular xenophobic insults and hate crimes launched right after the arrival of refugees in the village. In the 2019 municipal elections, the AfD gained more than $20 \%$ of the vote in Bad Gottleuba-Berggießhübel. What he wanted most was to "move away as soon as possible' - yet this was not permitted due to the movement restriction. The report also illustrates how the motivation to become exempt from the movement restriction through employment incentivized refugees like the interviewee to apply for

\footnotetext{
${ }^{9}$ In the SOEP survey, there are no items that directly ask refugees about their psychological reaction to the movement restrictions policy.
} 
jobs. Yet, bureaucratic hurdles prevented him from taking up employment in a different city. The refugee summarizes the effects that the movement restriction policy had on him as follows:

"I do not leave the house anymore (...) I don't care anymore. All of this destroyed my hope" 10

The individual cases cited above are typical examples of how the movement restriction policy decreased social engagement among refugees and their sense of belonging in German society.

\footnotetext{
${ }^{10}$ Original quote in German: "Ich gehe nicht mehr raus, sagt er. Es interessiert mich nicht mehr. Das alles hat meine Hoffnung kaputt gemacht".
} 


\section{References}

Abdelgadir, A. and V. Fouka. 2020. "Political Secularism and Muslim Integration in the West: Assessing the Effects of the French Headscarf Ban." American Political Science Review pp. 1-17. Acharya, Avidit, Kirk Bansak and Jens Hainmueller. 2021. "Combining Outcome-Based and Preference-Based Matching: A Constrained Priority Mechanism." Political Analysis pp. 1-24.

Adida, C. L., D. D. Laitin and M. Valfort. 2014. "Muslims in France: Identifying a Discriminatory Equilibrium." Journal of Population Economics 27(4):1039-1086.

Aksoy, Cevat Giray, Panu Poutvaara and Felicitas Schikora. 2020. First Time Around: Local Conditions and Multi-dimensional Integration of Refugees. SSRN Scholarly Paper ID 3738561 Social Science Research Network Rochester, NY: .

Alizade, Jeyhun and Fabio Ellger. 2020. "Do Politicians Discriminate Against Constituents with an Immigration Background? Field Experimental Evidence from Germany." SSRN Electronic Journal .

Åslund, Olof and Dan-Olof Rooth. 2007. "Do When and Where Matter? Initial Labour Market Conditions and Immigrant Earnings." The Economic Journal 117(518):422-448.

Bansak, Kirk, Jeremy Ferwerda, Jens Hainmueller, Andrea Dillon, Dominik Hangartner, Duncan Lawrence and Jeremy Weinstein. 2018. "Improving Refugee Integration through Data-Driven Algorithmic Assignment." Science 359(6373):325-329.

Barth, Rebecca. 2019. "Hasibullah, du bleibst hier!" https://www.fluter.de/was-diewohnsitzauflage-fuer-fluechtlinge-bedeutet.

BILD. 2016a. "DStGB: Länder müssen Wohnsitzauflage umsetzen." https://www.bild.de/regional/aktuelles/thueringen/dstgb-laender-muessen-wohnsitzauflageumsetzen-47752726.bild.html.

BILD. 2016b. "Streit um Wohnsitzauflage setzt sich fort." https://www.bild.de/regional/aktuelles/thueringen/streit-um-wohnsitzauflage-setzt-sichfort-47500794.bild.html.

BILD. 2016c. "Strobl will Flüchtlingen Wohnort vorschreiben." https://www.bild.de/regional/aktuelles/strobl-will-fluechtlingen-wohnort-vorschreiben- 
46698956.bild.html.

BILD. 2016d. "Zeitung: Stuttgart begrüßt geplante Wohnsitzauflage für Flüchtlinge." https://www.bild.de/regional/aktuelles/baden-wuerttemberg/zeitungstuttgart-begruesstgeplante-wohnsitzauflage-47644122.bild.html.

BILD. 2017. "Geldsorgen in der Flüchtlingskrise - Der dramatische Hilferuf der Kommunen." https://www.bild.de/politik/inland/fluechtlingskrise/kommunen-fordern-umverteilung-derintegrationspauschale-49566068.bild.html.

Bratsberg, B., J. Ferwerda, H. Finseraas and A. Kotsadam. 2020. "How Settlement Locations and Local Networks Influence Immigrant Political Integration." American Journal of Political Science pp. 1-15.

Bundeszentrale für politische Bildung. 2021. "Asylentscheidungen und Klagen — bpb." https://www.bpb.de/gesellschaft/migration/flucht/zahlen-zu-asyl/265711/entscheidungenund-klagen.

Cobb-Clark, D. A. 2003. "Public Policy and the Labor Market Adjustment of New Immigrants to Australia." Journal of Population Economics 16(4):655-681.

Cutler, D. M., E. L. Glaeser and J. L. Vigdor. 2008. "When Are Ghettos Bad? Lessons from Immigrant Segregation in the United States." Journal of Urban Economics 63(3):759-774.

Cutler, David M and Edward L Glaeser. 1997. "Are Ghettos Good or Bad?" Quarterly Journal of Economics p. 46.

Damm, A. P. 2014. "Neighborhood Quality and Labor Market Outcomes: Evidence from QuasiRandom Neighborhood Assignment of Immigrants." Journal of Urban Economics 79:139-166.

Damm, Anna Piil. 2009. "Ethnic Enclaves and Immigrant Labor Market Outcomes: QuasiExperimental Evidence." Journal of Labor Economics 27(2):281-314.

de Vroome, Thomas, Borja Martinovic and Maykel Verkuyten. 2014. "The Integration Paradox: Level of Education and Immigrants' Attitudes towards Natives and the Host Society." Cultural Diversity and Ethnic Minority Psychology 20(2):166-175.

Deutscher Bundestag. 2018. "Antwort Der Bundesregierung Auf Die Kleine Anfrage Der Abgeordneten Filiz Polat, Luise Amtsberg, Britta Haßelmann, Weiterer Abgeordneten Und Der Fraktion BÜNDNIS 90/DIE GRÜNEN.". 
Dinesen, P. T. and M. Hooghe. 2010. "When in Rome, Do as the Romans Do: The Acculturation of Generalized Trust among Immigrants in Western Europe." International Migration Review 44(3):697-727.

Edin, Per-Anders, Peter Fredriksson and Olof Åslund. 2003. "Ethnic Enclaves and the Economic Success of Immigrants - Evidence from a Natural Experiment." The Quarterly Journal of Economics 118(1):329-357.

Fleischmann, F. and J. Dronkers. 2010. "Unemployment among Immigrants in European Labour Markets." Work, Employment and Society 24(2):337-354.

Gillum, Rachel. 2018. Identity and Discrimination The Muslim American Experience. In Muslims in a Post-9/11 America: A Survey of Attitudes and Beliefs and Their Implications for U.S. National Security Policy. Ann Arbor, MI: University of Michigan Press.

Hausding, G. 2019. "Deutscher Bundestag - Uneins über Wohnsitzregelung." https://www.bundestag.de/dokumente/textarchiv/2019/kw23-pa-inneres-wohnsitzregelung644270 .

Hemker, Johannes and Anselm Rink. 2017. "Multiple Dimensions of Bureaucratic Discrimination: Evidence from German Welfare Offices: BUREAUCRATIC DISCRIMINATION." American Journal of Political Science 61(4):786-803.

Jaschke, Philipp, Sulin Sardoschau and Marco Tabellini. 2020. Scared Straight? Threat and Assimilation of Refugees in Germany. Unpublished.

Koslowski, Aylin. 2017. Eine qualitative Sozialforschung zu individuellen Integrationsstrategien von anerkannten Flüchtlingen in der Kleinstadt Bad Liebenzell PhD thesis.

Kuhn, Eroll and Rahsaan Maxwell. 2020. "Do Counties with More Foreign-Born Residents Make Asylum Seekers Feel More Welcome?" p. 83.

Marktforschung Axel Springer SE. 2021. "Media-Analyse Agma Media-Micro-Census." https://www.ma-reichweiten.de/.

Martén, L., J. Hainmueller and D. Hangartner. 2019. "Ethnic Networks Can Foster the Economic Integration of Refugees." Proceedings of the National Academy of Sciences 116(33):16280-16285.

Oskooii, Kassra AR. 2016. "How Discrimination Impacts Sociopolitical Behavior: A Multidimensional Perspective." Political Psychology 37(5):613-640. 
Rumbaut, Rubén G. 2008. "Reaping What You Sow: Immigration, Youth, and Reactive Ethnicity." Applied Developmental Science 12(2):108-111.

Steinmann, Jan-Philip. 2019. "The Paradox of Integration: Why Do Higher Educated New Immigrants Perceive More Discrimination in Germany?" Journal of Ethnic and Migration Studies 45(9):1377-1400.

Tani, Massimiliano. 2020. "Migration Policy and Immigrants' Labor Market Performance." International Migration Review 54(1):35-57.

van Doorn, Majka, Peer Scheepers and Jaco Dagevos. 2013. "Explaining the Integration Paradox Among Small Immigrant Groups in the Netherlands." Journal of International Migration and Integration 14(2):381-400.

WELT. 2017. "Wohnsitzauflage Für Flüchtlinge Beschäftigt Den Landtag." https://www.welt.de/regionales/niedersachsen/article164684830/Wohnsitzauflage-fuerFluechtlinge-beschaeftigt-den-Landtag.html.

White, Ariel R., Noah L. Nathan and Julie K. Faller. 2015. "What Do I Need to Vote? Bureaucratic Discretion and Discrimination by Local Election Officials." American Political Science Review 109(1):129-142.

Wir in NRW - Das Landesportal. 2016. "Wohnsitzauflage - Das Landesportal Wir in NRW." /de/pressemitteilung/minister-schmeltzer-das-land-unterstuetzt-mit-der-wohnsitzauflage-die. 